\title{
Estrutura da Competição pela Presidência e Consolidação do Sistema Partidário no Brasil*
}

\author{
Carlos Ranulfo Melo \\ Rafael Câmara ${ }^{2}$
}

${ }^{1}$ Professor e pesquisador do Departamento de Ciência Política da Universidade Federal de Minas Gerais (UFMG). E-mail: ranulfo@fafich.ufmg.br.

${ }^{2}$ Mestre em sociologia e doutorando no Programa de Pós-Graduação em Ciência Política da Universidade Federal de Minas Gerais (UFMG). E-mail: camaramelo@yahoo.com.br.

\section{INTRODUÇÃO}

$\mathrm{T}$

ranscorridas três décadas desde sua eleição inaugural o sistema partidário brasileiro continua despertando polêmica entre os que procuram analisá-lo. Como é sabido, o ceticismo predominou nas primeiras análises realizadas. Seja por razões que remetiam à trajetória histórica e a traços salientes de nossa cultura política, seja porque se superestimasse o impacto de alguns dos traços mais perenes do arranjo institucional sobre o processo decisório - como a representação proporcional de lista aberta e o federalismo - seja porque a análise se encontrasse centrada no período extremamente volátil situado entre meados dos anos 1980 e 1990, seja ainda porque a preocupação estivesse na fluidez constatada na relação entre os deputados e as organizações partidárias, o diagnóstico dominante a pontava para a fragilidade dos partidos e / ou para o quão pequenas seriam as chances de que o sistema partidário chegasse a um nível aceitável de consolidação (Lamounier, 1989; Abrucio, 1998; Sartori, 1994; Mainwaring, 1991, 1992, 1995 e 1999; Ames, 2001; Samuels, 2003; Melo 2004).

Mais recentemente a tendência se inverteu e passaram a predominar as análises que, enfatizando diferentes aspectos da questão, apontam

\footnotetext{
* Gostaríamos de expressar nossos sinceros agradecimentos aos pareceristas anônimos de DADOS. Suas cuidadosas observações em muito contribuíram para este artigo.
}

DADOS - Revista de Ciências Sociais, Rio de Janeiro, vol. 55, nํำ 1, 2012, pp. 71 a 117. 
para o fortalecimento dos partidos e do próprio sistema partidário. Uma série de autores, entre os quais se destacam Figueiredo e Limongi (1999, 2002 e 2007), têm mostrado que os partidos brasileiros sustentam de forma consistente os governos que apoiam e que, ademais, a própria relação entre o Poder Executivo e o Poder Legislativo tem sido conduzida em bases partidárias ${ }^{1}$. Comparando os dois períodos democráticos no Brasil, Lyne (2005) afirma que os atuais partidos possuem um comportamento mais programático, a despeito da manutenção do sistema eleitoral, e se portam de forma mais coerente do que a literatura costumava supor. Na mesma direção, Hagopian, Gervasoni e Moraes (2009) argumentam que o surgimento, nos anos 1990, de uma clivagem de ordem programática na política brasileira e a diminuição dos recursos disponíveis para a patronagem seriam os responsáveis por um comportamento mais partidariamente orientado dos deputados. A maior valorização do label partidário e o adensamento programático dos partidos seriam capazes de explicar por que os deputados estariam delegando autoridade a seus líderes no Congresso. Com base em uma série de surveys aplicados no Congresso Nacional entre 1990 e 2005, Power e Zucco (2008) afirmam ser possível distinguir de forma clara os principais partidos brasileiros com base em uma escala esquerda/direita e mostram que este ordenamento manteve-se constante a despeito das mudanças pelas quais o país passou em duas décadas. Finalmente, atentando para outra esfera, Melo $\left(2007\right.$ e 2010) ${ }^{2}$ e Limongi e Cortez (2010) destacam que a dinâmica adquirida pela disputa presidencial vem impactando de forma positiva a competição política no país e atuando como fator de estabilização e estruturação do sistema partidário.

A publicação de recente volume organizado por Power e Zucco (2011) trouxe novas contribuições ao debate. Valendo-se da mesma série de surveys utilizada na comunicação publicada em 2008, agora acrescida de uma nova rodada realizada em 2009, Zucco (2011:57-58) reafirma "que há bastante estabilidade na forma como os parlamentares se veem e como veem seus pares", mas ressalta a ocorrência de uma retração nas posições mais à esquerda. No contexto de tal convergência em direção ao centro, a ideologia estaria perdendo sua capacidade de estruturar as disputas no interior do Congresso e sendo substituída pela clivagem governo/oposição ${ }^{3}$.

Por sua vez, Lucas e Samuels $(2010,2011)$ retomam o ceticismo das primeiras análises. Utilizando os mesmos dados de Power e Zucco, os au- 
tores questionam a possibilidade de se traçar um mapa confiável do sistema partidário com base nas percepções dos deputados sobre a posição ideológica do seu e dos demais partidos. A conclusão é de que deveria ser colocada em dúvida a noção de que o sistema partidário vem se consolidando. Na verdade, como diz o texto, "nossos resultados sugerem exatamente o contrário [...], o sistema partidário brasileiro tem se tornado relativamente mais incoerente" (2011:61). O que leva os autores a chegar a esta conclusão? O fato de os dados analisados (1) não permitirem distinguir ideologicamente entre PSDB ${ }^{*}$, PMDB e DEM; (2) sugerirem que a única distinção possível é entre o "PT e o resto" e (3) mostrarem que mesmo esta distinção está diminuindo porque PT e DEM vêm se aproximando do centro.

Neste artigo seguimos a sugestão de Lucas e Samuels e retomamos o debate acerca do sistema partidário brasileiro. Indo direto ao ponto, sustentamos que a tese de que o sistema encontra-se mais incoerente hoje do que antes é equivocada. Fundamentalmente ela ignora que, a partir de 1994, a competição pela Presidência da República adquiriu um padrão estável, claramente identificável nas estratégias delineadas pelos partidos e que tal fato significa um sinal inequívoco de que, pelo menos em uma das dimensões possíveis de análise, o sistema partidário encontra-se hoje mais consolidado do que anteriormente.

Analisada a questão sob a ótica da competição pela Presidência de República, não deve causar nenhuma surpresa o fato de que seja difícil distinguir as opiniões dos parlamentares do PSDB e do DEM ou que o primeiro tenha derivado para a direita enquanto seu parceiro preferencial tenha realizado um movimento no sentido oposto. Por sua vez, PSDB e PMDB sempre foram partidos ideologicamente próximos, sem esquecer que o segundo é, desde algum tempo, mais bem caracterizado como "um agregado de interesses regionais precariamente unificados pela maximização de cargos no plano federal" (Melo, 2007) do que como uma sigla dotada de consistência programática. Em outras palavras, a distinção pretendida por Lucas e Samuels entre os três partidos parece menos relevante do que dá a entender o argumento.

Por outro lado, e aqui é preciso levar em conta também o artigo de Zucco (2011), antes de se computar o fenômeno da "convergência ao centro" como evidência de mazela do sistema partidário brasileiro, é

\footnotetext{
* Ver lista de siglas dos partidos políticos com os respectivos significados ao final do artigo.
} 
preciso considerar que, primeiro, tal movimento faz parte da estratégia dos partidos na competição pelo governo, como o caso do PT mostra de forma clara e, segundo, reflete uma tendência claramente constatada no âmbito das democracias contemporâneas. Ao fim e ao cabo, a caracterização do sistema partidário brasileiro como marcado pela disjuntiva "PT versus o resto" nos parece parcial e equivocada. Ela ignora que a competição pelo governo federal tem servido como ponto de amarração do sistema e que, com base nela, é possível outra leitura sobre como interagem os partidos brasileiros.

A nosso ver, a estrutura assumida pela competição em torno da Presidência da República permite identificar três, e não dois, blocos distintos no sistema partidário brasileiro. Como é claro desde há algum tempo, dois deles - PT, PSB, PDT e PC do B, de um lado, e PSDB, DEM e PPS, de outro - disputam de forma direta a Presidência da República. O terceiro agrupamento, composto por PMDB, PP, PTB e PR, se coloca estrategicamente, ainda que não ideologicamente, entre os anteriores. Para efeito de nosso argumento, o que torna estes últimos partidos "parecidos" é a disposição de participar de qualquer dos governos que se instale em Brasília".

Além desta introdução, o artigo conta com mais três seções e uma conclusão. Na próxima seção retomamos a questão de como avaliar o problema do grau de consolidação dos sistemas partidários nas novas democracias. Apresentamos as razões que nos levaram a trabalhar com o conceito de "estrutura da competição" (Mair, 1996 e 2006), ao invés de institucionalização (Mainwaring e Scully, 1995) e procuramos situar o sistema partidário brasileiro à luz do debate. A seguir discutimos como se estruturou a competição pela Presidência da República no Brasil e mostramos como os principais partidos definiram suas respectivas estratégias permitindo caracterizar, ao fim e ao cabo, três blocos distintos. Na terceira seção o foco se volta para a Câmara dos Deputados. Serão analisadas as opiniões de legisladores pertencentes aos três conjuntos de partidos anteriormente delineados. O material empírico é proveniente de dois surveys realizados pelo Centro de Estudos Legislativos do Departamento de Ciência Política, da Universidade Federal de Minas Gerais (DCP-UFMG) na Câmara dos Deputados, em 2005 e 2010, cobrindo as legislaturas correspondentes aos dois mandatos de Lula $^{5}$. O objetivo é mostrar que as percepções dos deputados pertencentes aos três blocos partidários são consistentes com o que ocorre na competição pelo governo federal, em um processo no qual, ademais da 
disjuntiva governo/oposição, a ideologia tem que ser levada em conta. $\mathrm{Na}$ conclusão retoma-se a discussão sobre a consolidação do atual sistema partidário.

\section{ESTRUTURA DA COMPETIÇÃO E CONSOLIDAÇÃO DE SISTEMAS PARTIDÁRIOS}

Sistemas partidários consolidados tendem a gerar melhores resultados do que aqueles que não atingem tal condição. O jogo político torna-se mais estável, menos permeável ao surgimento de outsiders e mais inteligível para o eleitor ampliando, em decorrência, as chances de que este último possa exercer algum controle sobre os representantes. Quanto a isso, não há discussão.

Mas como saber quando um sistema partidário encontra-se mais, ou menos, consolidado? Na opinião de Sartori (1996) um sistema dotado de "consolidação estrutural" seria aquele onde o eleitor, ao votar, orienta-se por um vínculo de lealdade e por uma imagem abstrata que faz dos partidos. Quando isso acontece os partidos passam a funcionar como "um sistema natural de canalização da sociedade política" ( $p$. 51). Sartori, no entanto, não nos fornece muitas pistas de como avaliar o estágio de determinada formação partidária. Avesso à utilização da noção de contínuo, limitou-se a dizer que "os partidos de massas são um bom indicador de um sistema de partidos estruturado" (1976:295).

A maneira como Sartori propôs a questão deixou pelo menos dois problemas. Por um lado, sua abordagem acaba por enfatizar em demasia o que o próprio autor chama de "impacto imobilizador das estruturas" (1976:294), deixando a descoberto o complicado problema da mudança. Sistemas consolidados devem ser capazes de se adaptar a mudanças no ambiente em que operam, sob o risco de quebra - como, aliás, bem mostra o caso venezuelano (Cavarozzi e Casullo, 2003; Levitsky, 2005). A referência remete a um dos critérios definidos por Huntington (1975) ao discutir o conceito de institucionalização: a disjuntiva adaptabilidade/rigidez. Para o autor, quanto mais rígido um sistema, maiores os riscos à sua estabilidade. O próprio Sartori (1976) depois de apontar a proximidade entre os dois conceitos - consolidação estrutural e institucionalização - ressalta a diferença neste ponto, mas não a discute, limitando-se a dizer que seu conceito é "mais simples e menos ambicioso" que o de Huntington. 
Por outro lado, ao lidar com o conceito de forma dicotômica e enfatizar a importância dos partidos de massa, Sartori "condenou" os sistemas partidários das novas democracias a um estado de "não consolidação" ${ }^{\prime \prime}$. Este segundo problema foi assinalado e enfrentado por Mainwaring e colaboradores, que passaram a defender a ideia de que o conceito de institucionalização teria sua utilidade ampliada desde que entendido como um contínuo e desdobrado em quatro dimensões (Mainwaring e Scully, 1995; Mainwaring, 1999; Mainwaring e Torcal, 2005, 2006; Mainwaring e Zoco, 2007). Mas a operacionalização do conceito logo se revelou problemática. Já no artigo de 2005, reconhecendo as "dificuldades de se obterem informações empíricas válidas comparáveis para todas as quatro dimensões em uma ampla gama de países" (p. 251), Mainwaring e Torcal se limitavam a trabalhar com duas delas: a estabilidade na competição eleitoral (medida por meio da volatilidade) e o enraizamento dos partidos na sociedade ${ }^{7}$.

Em artigo recente, Luna e Altman (2011) levam adiante a discussão ao questionar o conceito de institucionalização tal como utilizado por Mainwaring. São dois os pontos abordados. O primeiro retoma a observação feita originalmente por Bartolini e Mair (1990) no sentido de que a interpretação dos resultados do índice de volatilidade deve ser feita com cuidado; seja porque o indicador não é capaz de captar a "entrada e saída" de eleitores do sistema, seja porque pode haver problemas na passagem do plano micro para o nível agregado - um partido pode manter o mesmo total de votos de uma eleição para outra, mas eles podem corresponder a diferentes eleitores. A lembrança é importante na medida em que, dada a já referida dificuldade de se encontrarem dados comparáveis, a volatilidade tornou-se o principal indicador utilizado na literatura.

A segunda crítica é mais contundente e questiona a ideia de que o conceito de institucionalização dos sistemas partidários possa ser tratado de forma unidimensional. Em outras palavras, não haveria razão para supor que todos os quatro indicadores necessariamente "andem juntos". Isso abriria a possibilidade de que um sistema partidário se encontre "institucionalizado" em uma dimensão, mas não em outra. A alternativa, dizem os autores, seria trabalhar com um conceito bidimensional - uma dimensão remeteria à estabilidade da competição e outra remeteria ao enraizamento dos partidos. Um sistema completamente institucionalizado seria estável e enraizado. Mas o sistema poderia ser também estável e com raízes frágeis; volátil e enraizado ou volátil e de- 
senraizado. O Chile, analisado pelos autores, seria enquadrado no segundo caso: um sistema partidário estável no que se refere à competição eleitoral, mas frágil naquilo que diz respeito ao enraizamento e legitimidade dos partidos. O mesmo poderia ser dito sobre a Venezuela dos anos $1990^{8}$.

O artigo de Luna e Altman certamente contribui para que se avance na discussão de como saber que um sistema, no nosso caso o brasileiro, encontra-se mais, ou menos, consolidado. A "resposta" ao artigo de Lucas e Samuels poderia ser a de que o sistema partidário brasileiro encontra-se em situação similar à do Chile o que, aliás, os dois primeiros autores mencionam ${ }^{9}$. Mas, a nosso ver, o conceito de institucionalização, tal como utilizado na literatura, não é a ferramenta mais indicada para uma discussão a respeito do atual estágio do sistema partidário brasileiro.

Uma das razões remete ao uso do conceito de volatilidade para o plano federal. Tomemos o caso da Câmara dos Deputados. Analisando-se a votação nacional dos partidos é fácil perceber que a volatilidade para a Câmara diminuiu a partir das eleições de 1994. Segundo Rennó, Peres e Ricci (2008) os valores são 35,3 (86/82); 35,4 (90/86); 19,5 (94/90); 14,5 (98/94); 15,2 (02/98) e 10,2 (06/02). A eleição de 2010, por sua vez, gerou uma volatilidade de 9,9 (Meneguello, 2011). O problema é que, calculado desta forma, o índice pouco tem a dizer. A volatilidade procura medir a mudança eleitoral agregada entre duas eleições consecutivas, mas no Brasil, como sabemos, os votos são agregados no plano estadual e não no nacional. Se aplicado no plano estadual o indicador já apresenta os problemas anteriormente destacados (Bartolini e Mair, 1990), calculado com base na votação nacional a distorção aumenta: a diferença entre a votação nacional de um determinado partido de uma eleição a outra simplesmente obscurece o que de fato aconteceu nos estados. Analisando-se a votação para a Câmara dos Deputados nos estados, o cenário é muito mais diversificado. Para o par de eleições 2006/2002, por exemplo, a volatilidade varia de 14,0 em Santa Catarina até 58,6 no Amazonas, passando por 31,4 no Rio de Janeiro ou 31,8 no Ceará (Rennó, Peres e Ricci, 2008; Melo, 2011). E, em nenhum dos casos, a volatilidade medida com base na votação estadual é menor do que aquela obtida a partir dos dados nacionais ${ }^{10}$.

Poder-se-ia argumentar que a diminuição no índice de volatilidade medida nas eleições presidenciais resolveria o problema. Os valores 
são os seguintes: 58,6 (94/89); 17,8 (98/94); 33,6 (02/98); 30,4 (06/02) e $20,4(10 / 06)^{11}$. A queda é real, embora mais acentuada se tomarmos como ponto de partida a eleição de 1989; a partir de 1994 o índice mostra certa oscilação, sendo possível imaginar que vá se estabilizar na casa dos 20 pontos. Seja como for, o ponto mais importante é outro e remete à percepção de que a utilização do índice de volatilidade não é capaz de destacar o que realmente mudou no sistema partidário brasileiro ao longo dos últimos 20 anos. Na verdade a retração nos valores do índice é apenas uma consequência desta "novidade", qual seja, o surgimento de um determinado padrão de interação entre os partidos na competição pela Presidência da República.

A discussão pode ser feita com o auxílio do conceito de "estrutura da competição", formulado por Mair $(1996,2006)$, com o objetivo de distinguir sistemas partidários e possibilitar a percepção de mudanças em seu anterior. Segundo o autor, "o cerne de todo sistema partidário enquanto sistema é constituído pela estrutura da competição pelo controle do Executivo" (tradução livre)" (p. 65). Tal estrutura depende do padrão de alternância no governo, da fórmula governamental utilizada (dos processos de formação de governo) e de que partidos efetivamente participam da gestão. Um sistema como o norte-americano representa um caso limite: o padrão de alternância é previsível, o governo é sempre unipartidário e apenas dois partidos participam do jogo. Trata-se de uma estrutura fechada de competição. No outro extremo poderia figurar o caso peruano ou o equatoriano: países onde a competição pelo governo central tem se mantido totalmente aberta e pouco ou nada pode ser previsto sobre como se dará a alternância, que tipo de governo se instalará e mesmo quais partidos dele farão parte. A impossibilidade de se caracterizar a competição pelo governo, de definir seus atores e em torno do que se realiza a disputa seria, portanto, indicativa de um quadro partidário incipiente, dotado de baixa ou nenhuma sistematicidade ${ }^{12}$.

O caso brasileiro seria expressivo de uma situação onde, nos termos utilizados por Mair, "um conjunto de interações que antes era incoerente começa a ganhar forma e adquirir uma estrutura", o que poderia ser tratado, em diálogo com a abordagem adotada por Mainwaring, "como um caso de institucionalização do sistema partidário" (2006:66, tradução livre). De fato, a análise do atual período democrático revela que a clivagem autoritarismo/democracia, materializada na disputa entre PMDB e PDS nas eleições de 1982, rapidamente perdeu a capaci- 
dade de delimitar o espaço da competição partidária no país, o que possibilitou o surgimento de uma situação em que o resultado do jogo político encontrava-se completamente aberto - algo cabalmente demonstrado pelo fato de que o então pequeno PT e o quase inexistente PRN terminaram disputando o segundo turno da primeira eleição presidencial. Posteriormente, até o surgimento da candidatura de Fernando Henrique, o quadro manteve-se indefinido, não sendo possível definir em torno de que seria realizada a disputa pelo governo federal e quais seriam os seus protagonistas, a não ser, é claro, que entre os competidores estaria Lula. A superação deste quadro, com a redefinição do espaço da competição, seus protagonistas e suas estratégias, iria representar o fator decisivo para os rumos do sistema partidário brasileiro algo que, como já dito, a operacionalização do índice de volatilidade não conseguiria expressar. A competição em torno da Presidência da República passaria a ser estruturada em torno de duas coalizões ideologicamente distintas, inaugurando uma dinâmica com impacto sobre as escolhas de cada um dos partidos relevantes e sobre o grau de consolidação do sistema partidário.

Isso não pode ser lido, esperamos que esteja claro, como um sinal de que o sistema partidário brasileiro vá caminhar para uma situação de institucionalização plena, tal como delineada pela análise de Luna e Altman (2011). Os obstáculos para tanto não estariam apenas em nossa "cultura política" ou nas escolhas institucionais feitas ao longo de nossa trajetória como país independente, mas também no fato, fartamente aceito pela literatura, de que a época das organizações partidárias fortes e dotadas de perfil programático bem definido simplesmente passou (Manin, 1997; Panebianco, 1982, Katz e Mair, 1995 e 2002, Dalton e Wattemberg, 2002; Mair, 2006). Para utilizar os termos de Mainwaring e Zoco (2007:155, tradução livre): "o que importa, no que concerne à estabilização da competição partidária, é quando a democracia nasceu, não a sua idade".

O Brasil nunca experimentou uma "democracia de partido" (Manin, 1995). Regimes deste tipo só foram possíveis naqueles países onde os partidos chegaram a desempenhar papel relevante na mobilização e incorporação dos indivíduos à condição de cidadania e onde, na esteira de tal processo, criaram extensas redes de apoio e fortes laços de identidade entre o eleitorado. A história brasileira, no entanto, registra poucos momentos em que os partidos tenham sido protagonistas de escolhas cruciais. O país iniciou seus processos de state building e de in- 
corporação social, bem como definiu seus traços institucionais mais gerais - o sistema de governo, a forma de estruturação da União e o sistema eleitoral - anteriormente à existência de partidos nacionais.

O fato de que, pela primeira vez na história, os partidos brasileiros estejam operando no interior de uma democracia estável, e possam, portanto, se beneficiar de uma sequência mais longa de eleições, não tende a alterar o quadro geral no que se refere à relação entre eleitores e partidos. O "tempo" do atual sistema transcorrerá em um contexto em que os processos acima referidos - de mobilização e incorporação política já foram realizados e onde, nas democracias, a relação entre eleitores e partidos foi profundamente modificada por uma série de fatores, entre os quais merecem destaque o surgimento de novos issues e novos atores, a expansão das formas de participação e as radicais mudanças na forma de processar e transmitir as informações (Mainwaring e Zoco, 2007; Dalton e Wattenberg, 2002). Sem desconsiderar as diferenças entre os diversos países, a tendência geral é de uma queda nas taxas de identificação partidária e na capacidade de mobilização dos partidos, de um aumento no número de eleitores que operam de forma independente das siglas partidárias e de um incremento nos índices de volatilidade uma vez que os mercados eleitorais encontram-se mais abertos. Da mesma forma, aos atores políticos interessa menos que antes investir recursos no fortalecimento de máquinas partidárias que deixaram de ser decisivas: a comunicação com o eleitor pode ser feita de forma direta e as campanhas "trocaram" dirigentes partidários e militantes pelo uso intensivo de capital e por legiões de especialistas (Manin, 1995; Dalton e Wattenberg, 2002; Farrel, 2006).

Paralelamente a isso as democracias assistiram nos últimos 30 anos a uma diminuição das diferenças políticas entre os principais partidos, seja como consequência do fim do bloco socialista (e a perda de relevância dos partidos antissistema), seja como decorrência das limitações impostas aos governos, em especial aos eleitos pela esquerda, pelos princípios de austeridade fiscal e monetária. Neste contexto, como chamaram a atenção Katz e Mair $(1995,2002)$, todos os partidos relevantes, no ocidente, chegaram a participar dos governos de seus países, o que contribuiu para que eles tenham vindo a se aproximar uns dos outros e a se assemelhar cada vez mais às equipes de líderes competindo pelo voto popular nos moldes descritos por Schumpeter, Downs ou Epstein. Na opinião de Mair (2006:71), a tendência é que, seja nas novas seja nas velhas democracias, os sistemas partidários 
passem a ser caracterizados por uma competição de tipo bipolar envolvendo "blocos de partidos ou coligações eleitorais mais ou menos flexíveis e maleáveis, em vez de partidos isolados ou coalizões coesas. Tudo o mais permanecendo o mesmo, esses blocos poderão ser caracterizados como sendo de centro-esquerda e centro-direita, embora na prática possa haver pouca coisa, em termos de políticas governamentais, a distingui-los" (tradução livre).

Ao fim e ao cabo, a melhor aposta para o sistema partidário brasileiro parece ser um quadro em que uma competição estruturada entre dois blocos não muito distantes do ponto de vista ideológico conviva com um quadro de baixa legitimidade dos partidos e de fluidez nas relações entre estes e os eleitores. Sendo assim, é preciso relativizar o impacto da constatação de que partidos situados ao centro e à direita do espectro político nacional são "indistinguíveis" (Lucas e Samuels, 2010, 2011). A métrica com que avaliamos os partidos e o sistema partidário brasileiro não pode ser a mesma utilizada pela literatura para analisar a situação nas democracias mais antigas.

\section{PARTIDOS, ESTRATÉGIAS E ESTRUTURA DE COMPETIÇÃO NO BRASIL}

Eleições presidenciais e sistemas partidários podem se reforçar ou se fragilizar mutuamente. Se o jogo presidencial é conduzido pelos partidos políticos, é possível que a sequência das eleições gere uma retroalimentação de caráter positivo e funcione como elemento de estruturação do sistema partidário, credenciando alguns e descredenciando outros competidores aos olhos dos eleitores e demais atores. Se, por outro lado, as eleições passam a ser conduzidas por lideranças apoiadas por movimentos ad hoc, temos o efeito inverso, e a sequência de eleições deslegitima os partidos e inicia, ou acelera, o processo de desestruturação do sistema partidário - como ilustram os casos de Equador, Peru, Venezuela, Colômbia, Argentina e Bolívia em períodos recentes. Deste modo, pode-se dizer que a presença dos partidos na condução do jogo político naquela que, no caso de regimes presidencialistas, é a principal arena da disputa, é condição necessária para que o sistema partidário possa apresentar algum grau de estruturação.

No caso do Brasil, o jogo presidencial é controlado pelos partidos e o sequenciamento das eleições definiu de forma nítida os competidores e suas estratégias. Entre os maiores partidos brasileiros apenas PT e PSDB apresentam de forma consistente uma "vocação presidencial", 
tendo lançado candidatos competitivos em todos os pleitos e passando a constituir os dois polos inequívocos da disputa a partir de $1994^{13}$. Ao fim e ao cabo, as eleições presidenciais brasileiras tornaram-se "eficientes", no sentido conferido ao termo por Shugart e Carey (1992), possibilitando aos eleitores uma escolha entre propostas alternativas de políticas nacionais (Melo, 2007; Miranda, 2009).

O fato de que PT e PSDB constituem os polos da disputa não é, a esta altura, nenhuma novidade. O que não foi devidamente explorado é por que apenas para PSDB e PT a arena presidencial se tornou a principal e por que isso não foi possível para PDT, PMDB e DEM. Parte da resposta pode ser dada se concordarmos que processos de desenvolvimento político envolvem conjunturas críticas e mecanismos de path dependence; as primeiras referindo-se a momentos fundacionais que encaminham os países ao longo de diferentes rotas e os segundos sugerindo que as instituições continuam a se desenvolver em resposta a mudanças no ambiente externo e no processo político, mas sob o constrangimento das escolhas passadas (Thelen, 1999:387).

Neste sentido as eleições de 1989 e 1994 podem ser apontadas como eventos críticos, eventos cujos resultados tiveram impacto decisivo sobre a dinâmica subsequente da disputa presidencial no país. Por um lado, as duas eleições definiram a disputa entre PT e PDT pela liderança no campo da esquerda. Uma das razões para o naufrágio da segunda candidatura presidencial de Brizola deve ser buscada no resultado de cinco anos antes: para uma expressiva parcela do eleitorado, o voto em 1994 foi fortemente influenciado pelo desempenho de Lula no segundo turno em 1989: quem havia votado em Lula dificilmente teria razões para voltar a Brizola cinco anos depois.

A eleição de 1994 garantiu ainda, ao PSDB, a conquista de um lugar na competição presidencial com base em duas ações articuladas. A primeira, e essencial, foi a exitosa introdução do imperativo da estabilidade econômica e da austeridade fiscal na agenda nacional. A segunda foi um movimento de caráter ideológico rumo à direita (Roma, 2002) para celebrar uma aliança com o então PFL e o PTB. Feito isso, o partido definiria o seu projeto político para o país e provocaria uma nova alteração no espaço da competição, assumindo a centralidade que coubera ao PMDB no processo de transição e tornando evidente o anacronismo do discurso petista baseado na afirmação de uma alternativa de oposição radical "a tudo o que aí está". A partir de 1994 a competição política 
nacional passaria a ocorrer no interior de um espectro ideológico mais comprimido, assumindo a atual dinâmica moderada.

A outra parte da resposta deve ser buscada nos próprios partidos. Neste caso, importa ressaltar, novamente com Thelen (1999), que conjunturas críticas não geram legados de forma mecânica. É preciso que exista um "mecanismo de reprodução". E, no nosso caso, este deve ser encontrado na ação de petistas e tucanos. Dentre os maiores partidos brasileiros, PT e PSDB foram os únicos a se mostrarem capazes de (1) formular um projeto de política nacional, (2) apresentar candidatos competitivos às eleições presidenciais e (3) se unificar em torno de (1) e (2).

PT e PSDB sempre tiveram claro que as decisões tomadas na arena principal - a presidencial - deveriam subordinar as demais. Mas, pelo menos até 2002, isso teve consequências distintas para os dois partidos. Mesmo antes da primeira eleição presidencial, a estratégia petista sempre foi claramente nacional - tratava-se de firmar um projeto político, de levar o partido ao maior número de estados possível, correndo em faixa própria com seus símbolos e seu discurso. Preso a uma política de alianças articulada sob o ponto de vista do "campo democrático e popular", o partido, até 2002, simplesmente vetava toda e qualquer aliança com partidos situados ao centro e à direita. Contando apenas com o apoio dos pequenos partidos de esquerda e com poucas lideranças regionalmente competitivas, o PT limitava-se a reproduzir o palanque de Lula nos estados - era a campanha de Lula que sustentava a mobilização estadual e não o contrário ${ }^{14}$. A partir de 2002, a articulação entre a disputa nacional e as estaduais passou a ser vista de forma distinta e apenas a verticalização imposta pelo Tribunal Superior Eleitoral (TSE) inibiu a diminuição do número de candidaturas nos estados. Em 2010, superada a disposição do TSE, o PT lançou apenas 10 candidatos a governador, cedendo espaço, sempre que necessário, a seu parceiro na chapa nacional, o PMDB.

No caso do PSDB a candidatura presidencial sempre procurou apoio em candidatos estaduais competitivos, fossem eles do PSDB ou não. Em consequência, o número de candidaturas próprias aos governos estaduais, entre 1990 e 2010, foi bem menor que os lançados pelo PT. Se para os petistas a vinculação entre a estratégia presidencial e o desempenho nas eleições para a Câmara pode ser feita de forma mais direta a associação entre Lula e a legenda foi decisiva para o crescimento da 
bancada federal - para os tucanos, o desempenho nos estados aparece como fator intermediário "puxando", mais do que o candidato presidencial, a bancada federal ${ }^{15}$.

Seja como for, desde 1994 apenas PSB, PPS e PV chegaram a realizar tentativas críveis de romper a bipolarização. Os dois primeiros casos podem ser explicados com base na mesma conjunção de fatores: (a) as pretensões de Ciro Gomes e Garotinho, lideranças para as quais a filiação a esta ou aquela legenda sempre dependeu das circunstâncias ${ }^{16}$; (b) a pressão exercida pela expectativa, posteriormente revertida, de entrada em vigor da cláusula de desempenho de 5\%; e (c) a necessidade de encontrar um espaço próprio no cenário político fugindo, deste modo, da "sombra" do PT. No caso do PV, o rompimento de Marina com o governo Dilma fez com que o partido "achasse" uma candidatura. Estes fatores foram suficientes para que os três partidos participassem de forma episódica da disputa presidencial, mas não para que fizessem desta a sua arena principal.

Na medida em que se delineou o novo espaço da competição e ficou claro quais seriam os principais competidores, os demais partidos passaram a estabelecer suas estratégias de sobrevivência e para isso tiveram que definir (a) onde apostariam suas fichas e (b) como se posicionar diante do jogo presidencial. O que há de peculiar no quadro brasileiro é que, como as eleições são aninhadas e o presidencialismo é de coalizão, tomar como prioritária a disputa pelos governos estaduais ou mesmo a eleição de boas bancadas no Congresso não implica uma saída do jogo presidencial, mas apenas subordinar os movimentos nesta última arena às necessidades ditadas em uma das outras duas (Melo, 2010).

A opção feita pelo DEM no sentido de uma aliança prioritária com o PSDB não significava, a princípio, que o partido abriria mão da disputa presidencial. Os democratas possuem um projeto político nacional, de matiz neoliberal, sempre apresentaram um considerável grau de unidade e durante um bom período mantiveram no horizonte a possibilidade de uma candidatura própria. Se esta alternativa não se configurou, estabelecendo uma disputa no interior do bloco, foi porque uma série de fatores impediu que o partido viabilizasse um candidato competitivo. A ausência de candidato próprio não impediu que o bom desempenho nas disputas estaduais tivesse como desdobramento a eleição de fortes bancadas no Congresso. Pelo menos até 2002. A partir 
daquela eleição, a opção em manter-se na oposição aos governos petistas custou caro ao partido, que viu PT e PSB crescerem no Nordeste e perdeu espaço no Congresso. A criação do PSD, em 2010, apenas confirma a trajetória descendente da legenda. O partido tornou-se, de forma definitiva, um coadjuvante do PSDB e um competidor apenas ocasional nas disputas pelos governos estaduais ${ }^{17}$. Resta-lhe como estratégia de sobrevivência priorizar as eleições proporcionais. O mesmo vale para o PPS. No atual contexto, o bloco PSDB/DEM/PPS encontra-se tensionado pelo baixo desempenho dos dois "sócios menores" o que, não sendo revertido, permite prever uma fusão dos três partidos sob a égide do PSDB.

PT, PSB, PC do B e PDT atuam de forma articulada desde a eleição presidencial de $1989^{18}$. Inicialmente o foco de tensão esteve na relação entre petistas e pedetistas. A sorte do PDT foi definida em dois lances: na derrota para o PT na disputa pela lideranca do campo e posteriormente na perda de competitividade nos estados do Rio de Janeiro e Rio Grande do Sul. Em sentido contrário, aparece o PSB. Desde 1990, quando lançou apenas um candidato, o partido ampliou sua presença nas disputas pelos governos estaduais até que esta se firmasse como sua arena prioritária. Em 2006 foram dez candidaturas próprias e em 2010 oito, seis das quais vitoriosas. A prioridade conferida à disputa dos governos estaduais como a estratégia por excelência do partido ficou clara em 2006: mesmo depois de participar do primeiro governo Lula, os socialistas, na vigência da verticalização, se recusaram a aderir formalmente à coligação petista, garantindo sua liberdade de movimento nos estados. A estrategia foi bem sucedida e o crescimento do PSB representa para o futuro próximo um ponto de tensão no interior do bloco ${ }^{19}$.

De forma distinta, PMDB, PP, PTB e PR estabeleceram suas estratégias sem necessidade de assumir um dos lados da disputa presidencial, mas cientes de que a eleição de uma bancada de tamanho médio a grande seria suficiente para torná-los aliados potenciais no plano federal. No caso do PMDB, o potencial de coalizão se viu ampliado graças ao sucesso do partido na sua arena prioritária - as disputas majoritárias estaduais. Incapazes de se unificar em torno de uma proposta e de um candidato, os peemedebistas abandonaram a pretensão de disputar a Presidência - ainda que formalmente sempre se mencione a possibilidade de uma candidatura própria. A estratégia possibilitou manter o precário equilíbrio no interior do partido, mas como seria de se esperar, em situações de conflito, as decisões nacionais foram tomadas le- 
vando em conta a lógica estadual ${ }^{20}$. O partido venceu $53,4 \%$ das eleições em que participou e elegeu 62 governadores entre 1986 e 2010. A capacidade de lançar candidatos competitivos nos estados manteve o PMDB na condição de partido pivotal no processo decisório nacional ao influenciar o desempenho nas eleições para a Câmara dos Deputados. Entre 1990 e 2010 o partido elegeu respectivamente oito, nove, seis, cinco, sete e cinco governadores. No mesmo período, a bancada na Câmara atingiu 108, 107, 83, 74, 89 e 79 deputados. Onde a legenda perdeu espaço na disputa para o governo estadual, como em São Paulo, Minas Gerais, Bahia e Goiás, o peso da bancada estadual na composição da nacional diminuiu sensivelmente.

PP, PTB e PR, por sua vez, apostam de forma quase exclusiva nas eleições para o Congresso como forma de se bancar no jogo presidencial. Até 1994, o PP ainda aparecia como competidor pelos governos estaduais. Desde então foram poucos os candidatos lançados e raras as vitórias. O PTB esteve à frente de um governo estadual enquanto o PR nem isso.

Na sequência das eleições presidenciais a interação entre os principais partidos brasileiros adquiriu um caráter sistêmico e hoje é possível delinear, com clareza, qual a estratégia de cada jogador. Por um lado, existem estratégias distintas, quer os partidos priorizem a arena nacional, a estadual ou a legislativa. Por outro, o sistema partidário nacional se estruturou em torno de dois polos - um capitaneado pelo PT com participação do PC do B, PSB e PDT; outro constituído pela aliança PSDB/DEM, à qual recentemente aderiu o PPS. Tal como em muitos sistemas partidários nas democracias ocidentais, o jogo é jogado entre as posições de centro-esquerda e centro-direita. Tudo isso aponta de forma clara para um sistema hoje mais consolidado do que antes. $\mathrm{O}$ que talvez seja peculiar no caso brasileiro é a existência, entre os dois "pontos de amarração", de um terceiro conjunto de partidos - PMDB, PP, PTB e PR - que, valendo-se das bancadas eleitas para o Congresso, têm em comum a disposição e a possibilidade de aderir ao governo de plantão. Isso permite caracterizar o sistema partidário brasileiro como dotado de uma estrutura aberta de competição, na qual os dois polos tendem a se alternar, mas na forma de coalizões flexíveis já que os "sócios menores" não são rigidamente definidos. 


\section{ANALISANDO OS SURVEYS: COMO SE POSICIONAM OS BLOCOS PARTIDÁRIOS NO CONGRESSO}

Nesta seção nos voltamos para o interior da Câmara dos Deputados e, com base nas percepções dos deputados tais como captadas nos surveys realizados, procuramos distinguir as posições dos três conjuntos de partidos definidos na seção anterior. Nas democracias é comum haver diferenças entre os sistemas partidários eleitorais e os parlamentares $^{21}$. Desta forma faz sentido verificar se, e até que ponto, a estrutura da competição pela Presidência da República se manifesta na Câmara. A literatura tem explorado de maneira sistemática o comportamento de partidos e deputados no legislativo federal: sabemos que os partidos que compõem o "núcleo duro" dos dois polos da competição eleitoral nacional têm integrado coalizões governamentais distintas e que, ademais, as diversas bancadas agem de forma disciplinada no Congresso Nacional ${ }^{22}$. Levar em conta as percepções dos parlamentares, por sua vez, permite uma aproximação complementar ao que acontece no Legislativo. Como destacam Power e Zucco (2011:15), "a racionalização e a justificação para o comportamento, oferecidas pelos próprios congressistas, são parte integral e importante do significado da atividade legislativa". Em nosso caso, o objetivo será o de mostrar, com base em um conjunto de questões selecionadas, que os blocos $\mathrm{PT} / \mathrm{PSB} / \mathrm{PC}$ do B/PDT e PSDB/DEM/PPS são distinguíveis, como o terceiro conjunto de partidos se posiciona face aos dois primeiros e até que ponto as clivagens ideologia, de um lado, e governo/oposição, de outro, são capazes de explicar as diferenças constatadas.

Analisaremos os posicionamentos dos deputados no que se refere ao papel do estado na economia, a temas como aborto e união civil de pessoas do mesmo sexo, à política externa, ao sistema eleitoral e à relação dos deputados com os partidos. No que se refere aos dois primeiros conjuntos de questões a importância é óbvia - são temas que demarcam campos e costumeiramente frequentam os debates nas campanhas eleitorais e/ ou no Legislativo. As questões referentes ao sistema eleitoral há muito fazem parte de forma sistemática da agenda política brasileira. A relação entre partidos e deputados possui consequências práticas, como resultado da tensão entre a forma como são eleitos os deputados - a lista aberta - e o caráter centralizado dos trabalhos no Congresso Nacional. A política externa, por sua vez, é um tema que dividiu opiniões ao longo de todo o governo Lula. Como mostram Power e Zucco (2011:25), o survey aplicado em 2009 revela que, entre as ques- 
tões que, na opinião dos congressistas, mais possibilitam distinguir entre os governos FHC e Lula, está a política externa. Embora seja cedo para afirmar se estamos diante de uma divisão mais duradoura, o fato é que o ponto adquiriu relevância no período aqui analisado, o que a nosso ver justifica sua inclusão na análise.

Para compararmos as opiniões dos deputados pertencentes aos três blocos de partidos sobre os temas referidos, adotamos os seguintes procedimentos estatísticos. Primeiramente, utilizamos o teste ANOVA para determinar se há diferenças estatisticamente significantes entre as médias dos grupos ${ }^{23}$. Nos casos em que estas diferenças são constatadas, fizemos uso do teste Tukey's HSD (Honestly Significant Difference) para determinar quais médias são diferentes.

Após a verificação da significância estatística, investigamos a significância substantiva das diferenças constatadas. Para tanto, analisamos o quanto as médias das opiniões dos deputados de cada bloco partidário se distanciam da média geral de cada variável. Como algumas questões dos surveys apresentam diferentes escalas de resposta, optamos por apresentar os resultados a partir dos escores $\mathrm{Z}$ padronizados de cada bloco partidário ${ }^{24}$.

Passemos então à análise das opiniões dos deputados com relação ao papel que o Estado deve ocupar na economia. Para examinar essa questão, colocamos em tela cinco perguntas, sendo as duas primeiras do survey realizado em 2005 e as outras três de 2010. A formulação das questões "ECON1" e "ECON3" é a mesma; apenas a escala foi alterada entre um survey e outro. Como os resultados serão discriminados por survey decidimos mantê-las como questões distintas.

- ECON1. O(a) senhor(a) poderia me dizer se é mais favorável a uma economia regulada pelo Estado ou pelo mercado? Utilize a seguinte escala, em que 1 indica "máxima presença do Estado na economia" e 5, "máxima liberdade para o mercado".

- ECON2. Qual dos critérios a seguir sintetiza sua atitude pessoal em relação ao tema das privatizações dos serviços públicos? 1. Privatizaria todos os serviços públicos. 2. Privatizaria todos os serviços públicos com exceção dos que tivessem maiores consequências para a maior parcela da população. 3. Só privatizaria aqueles serviços públicos de pouca rentabilidade. 4 . Não privatizaria nenhum serviço público. 
- ECON3. O(a) Sr(a) poderia me dizer se é mais favorável a uma economia regulada pelo Estado ou pelo mercado? Utilize a seguinte escala, em que 1 indica "máxima presença do Estado na economia" e 10, "máxima liberdade para o mercado".

- ECON4. Qual é, na opinião do(a) Sr(a), o nível de controle que o Estado deve ter sobre a gestão de serviços públicos como água, eletricidade ou transporte, entre outros. Utilize a seguinte escala, em que 1 significa que "os serviços públicos devem ser prestados e gerenciados pelo Estado", e 10, que "os serviços públicos devem ser prestados e gerenciados por empresas privadas".

- ECON5. Que nível de controle o Estado deve ter sobre os recursos naturais como gás, petróleo ou os minerais? Utilize a seguinte escala, em que 1 significa que "os recursos naturais devem ser explorados e gerenciados pelo Estado" e 10, que "os recursos naturais devem ser explorados e gerenciados por empresas privadas".

A Tabela 1 nos mostra os resultados dos testes de significância estatística, bem como o ordenamento das preferências dos partidos políticos com relação à atuação do Estado na economia. Os valores de F são referentes à significância estatística do teste ANOVA. Da mesma forma, os valores das três últimas colunas dizem respeito à significância estatística dos testes de TUKEY para cada par de médias dos blocos partidários.

Tabela 1

Opinião dos Parlamentares sobre o Papel do Estado na Economia

\begin{tabular}{|c|c|c|c|c|c|c|}
\hline \multirow[t]{2}{*}{ Survey } & \multirow[t]{2}{*}{ Variável } & \multirow[t]{2}{*}{$\mathbf{F}$} & \multirow{2}{*}{$\begin{array}{l}\text { Preferência por maior } \\
\text { presença do Estado }\end{array}$} & \multicolumn{3}{|c|}{ TUKEY'S HSD } \\
\hline & & & & $P T \backslash P S D B$ & $P T \backslash P M D B$ & PMDB $\backslash P S D B$ \\
\hline \multirow[t]{2}{*}{2005} & 1 & $* * 0$ & $\mathrm{PT}>\mathrm{PSDB}>\mathrm{PMDB}$ & ${ }^{* *} 0$ & ${ }^{* *} 0$ & ${ }^{*} 0,04$ \\
\hline & 2 & $* * 0$ & $\mathrm{PT}>\mathrm{PMDB}>\mathrm{PSDB}$ & $* * 0$ & $* * 0$ & 0,58 \\
\hline \multirow[t]{3}{*}{2010} & 3 & $* * 0$ & $\mathrm{PT}>\mathrm{PSDB}>\mathrm{PMDB}$ & $* * 0$ & $* * 0$ & 0,88 \\
\hline & 4 & $* * 0$ & $\mathrm{PT}>\mathrm{PMDB}>\mathrm{PSDB}$ & $* * 0$ & ${ }^{*} 0,02$ & 0,05 \\
\hline & 5 & $* * 0$ & $\mathrm{PT}>\mathrm{PMDB}>\mathrm{PSDB}$ & $* * 0$ & $* * 0$ & 0,78 \\
\hline
\end{tabular}

Elaboração dos autores.

${ }^{*} \mathrm{p}<0,05 ;{ }^{* *} \mathrm{p}<0,01$

Podemos observar que em todas as questões o bloco do PT foi o que se mostrou mais favorável à presença de um Estado mais atuante na economia. Os testes de significância apontam que, nas cinco questões mencionadas, é possível identificar uma diferença entre as opiniões 
Gráfico 1

Escores Padronizados das Opiniões dos Deputados sobre o Papel do Estado na Economia

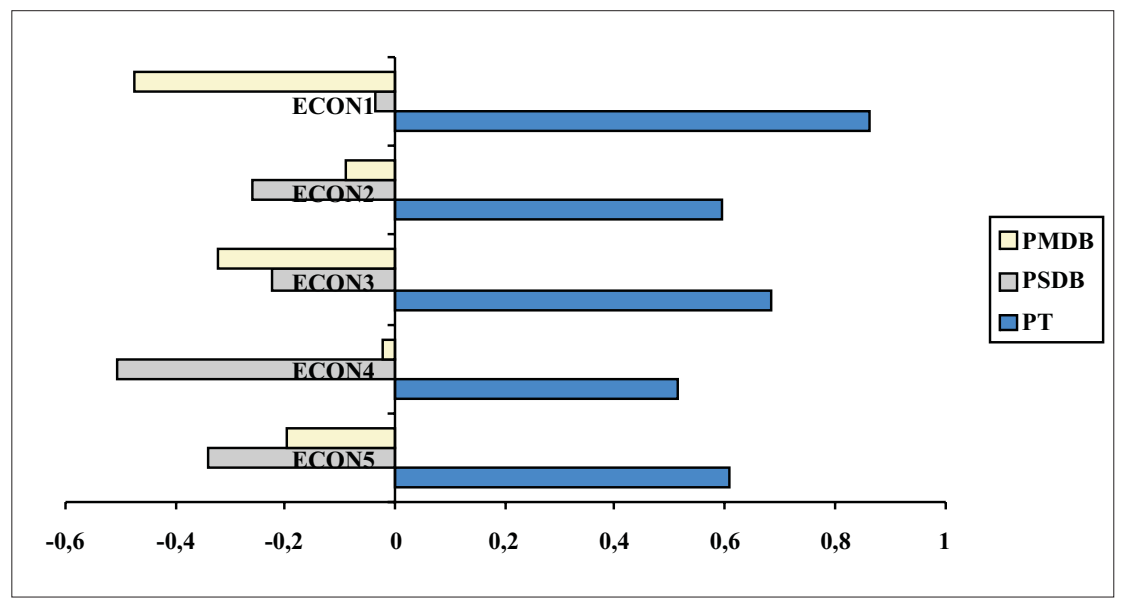

Elaboração dos autores.

dos parlamentares desse bloco em relação aos outros dois. Por sua vez, PSDB e PMDB apresentam posições semelhantes em quatro das cinco questões, ao ponto de suas opiniões médias não serem significativamente diferentes do ponto de vista estatístico.

Uma vez que constatamos a existência de diferenças entre as opiniões dos blocos partidários, passemos para a análise do tamanho dessas diferenças. O Gráfico 1 apresenta em escore padronizado (Z) as diferenças entre as opiniões médias dos blocos partidários com relação à média geral.

É fácil perceber que o bloco liderado pelo PT se distingue fortemente dos demais. Em nenhuma das questões houve uma diferença inferior a meio desvio padrão entre a média do primeiro bloco e aquela encontrada para os demais. Tanto em 2005, como em 2010, o bloco PSDB/DEM/PPS revela-se ligeiramente mais favorável à presença do estado na economia do que o bloco PMDB/PP/PTB/PR quando a questão é formulada de forma genérica (ECON1 e ECON3), mas apenas no primeiro momento a diferença é estatisticamente significativa. Quando a pergunta é feita de forma mais específica (ECON2, 4 e 5), a posição dos dois blocos se inverte, mas sem que a diferença seja significativa. 
O segundo tema por meio do qual podemos distinguir as opiniões dos parlamentares é a política externa. Com base nos dados dos surveys procuramos distinguir o posicionamento dos deputados em relação às questões internacionais com base em quatro questões: (1) o interesse a ser demonstrado pelo Brasil nas relações com determinados países ou regiões, (2) a importância do Tratado de Livre Comércio com os Estados Unidos para a América Latina (ALCA); (3) a avaliação da Aliança Bolivariana para a América Latina e Caribe (ALBA) e (4) a avaliação que os parlamentares fazem de líderes políticos internacionais. A primeira questão está elaborada da seguinte maneira no questionário de 2005:

- EXT. Em sua opinião, com relação às áreas e países enumerados em seguida, quanto interesse o governo brasileiro deveria ter ao formular sua política externa: muito interesse, interesse médio, pouco interesse ou nenhum interesse?

- EXT1. Países vizinhos

- EXT2. América Latina

- EXT3. Estados Unidos ${ }^{25}$

As questões referentes à ALCA e ALBA foram retiradas do questionário aplicado em 2010 e continham o seguinte enunciado:

- EXT4. Qualé, na opinião do(a) Sr.(a), o grau de interesse do Brasil em pertencer à ALCA: muito interesse, interesse médio, pouco interesse ou nenhum interesse?

- EXT5. Na seguinte escala, onde 1 significa "muito negativo" e 10, "muito positivo", como o(a) Sr(a) avalia o papel da Alternativa Bolivariana para América Latina e Caribe (ALBA)?

A Tabela 2 mostra que, novamente, os parlamentares dos blocos do PT e do PSDB apresentam posições nitidamente distintas e que podem ser descritas como estatisticamente significativas em todas as questões. Os parlamentares do bloco do PMDB, por sua vez, ora apresentam diferenças significativas relativamente aos primeiros (EXT3, ALCA e ALBA), ora aos segundos (EXT1 e EXT2).

Os escores padronizados do Gráfico 2 permitem que observemos a magnitude da diferença entre os blocos. Enquanto os parlamentares do bloco do PT demonstram maior apoio à formulação de políticas voltadas para os países vizinhos e da América Latina, rejeitam a ALCA e avaliam de forma positiva a ALBA, os deputados do bloco do PSDB se 
Tabela 2

Opinião dos Deputados sobre as Áreas/Países em que o Governo Deveria Ter mais Interesse em Formular sua Política Externa

\begin{tabular}{|c|c|c|c|c|c|c|}
\hline \multirow[t]{2}{*}{ Survey } & \multirow[t]{2}{*}{ Variável } & \multirow[t]{2}{*}{$\mathbf{F}$} & \multirow{2}{*}{$\begin{array}{l}\text { Área/país de inte- } \\
\text { resse }\end{array}$} & \multicolumn{3}{|c|}{ TUKEY'S HSD } \\
\hline & & & & $\mathrm{PT} \backslash \mathrm{PSDB}$ & $P T \backslash P M D B$ & PMDB $\backslash P S D B$ \\
\hline \multirow[t]{3}{*}{2005} & EXT1 & ${ }^{* *} 0,01$ & $\mathrm{PT}>\mathrm{PMDB}>\mathrm{PSDB}$ & ${ }^{* *} 0,01$ & 0,57 & ${ }^{* *} 0,01$ \\
\hline & EXT2 & ${ }^{* *} 0,01$ & $\mathrm{PT}>\mathrm{PMDB}>\mathrm{PSDB}$ & ${ }^{* *} 0$ & 0,26 & ${ }^{*} 0,02$ \\
\hline & EXT3 & $* * 0$ & $\mathrm{PSDB}>\mathrm{PMDB}>\mathrm{PT}$ & $* * 0$ & $* * 0$ & 0,55 \\
\hline \multirow[t]{2}{*}{2010} & ALCA & ${ }^{* * 0}$ & $\mathrm{PT}<\mathrm{PMDB}<\mathrm{PSDB}$ & ${ }^{* *} 0$ & $* * 0$ & 0,98 \\
\hline & ALBA & $* * 0$ & $\mathrm{PSDB}<\mathrm{PMDB}<\mathrm{PT}$ & $* * 0$ & $* * 0$ & 0,08 \\
\hline
\end{tabular}

Elaboração dos autores.

\section{Gráfico 2}

Escores Padronizados das Opiniões dos Deputados sobre os Países em que o Governo Deveria Ter Interesse em Formular sua Política Externa

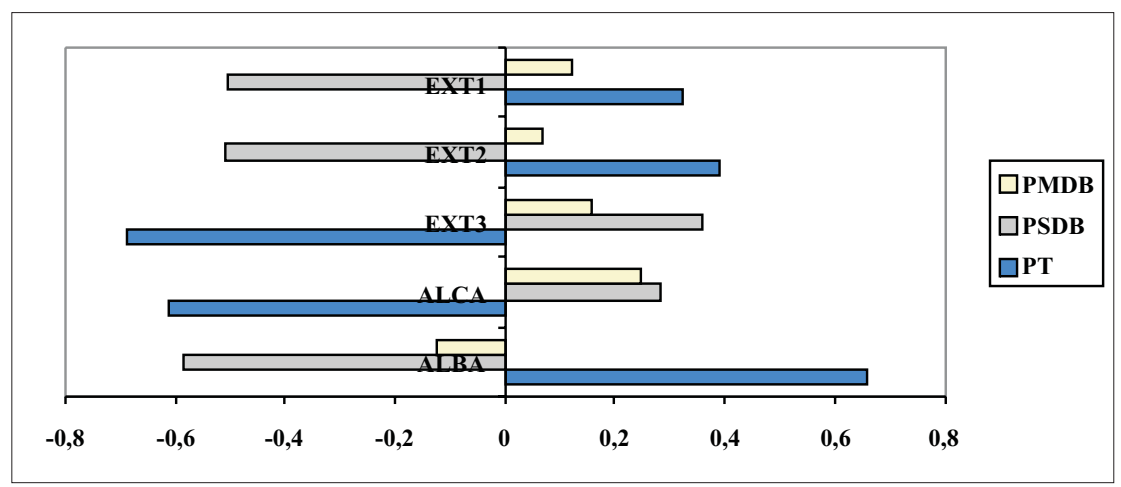

Elaboração dos autores.

mostram mais favoráveis à formulação de políticas voltadas para as relações com os EUA. A posição média do bloco do PMDB aproxima-se dos petistas e seus aliados no que se refere à relação com a América Latina e países vizinhos, mas assemelha-se à encontrada para o bloco do PSDB quando os deputados são perguntados sobre os EUA.

No survey de 2010, a questão sobre o interesse do Brasil nas relações com determinados países ou regiões foi reelaborada e passou a ter o seguinte formato:

- EXT6. Com referência às relações internacionais das áreas e países listados, qual é, na opinião do(a) Sr(a), a área prioritária na qual o governo brasileiro deveria formular sua política externa? 1. Os países 
vizinhos; 2. Os países da América Latina em geral. 3. Os Estados Unidos; 4. O Japão; 5. A China; 6. A União Europeia.

Para o artigo, optamos por agregar tanto as alternativas 1 e 2 como as de número 4, 5 e 6 . Desta forma, passamos a trabalhar com três alternativas: 1. Países vizinhos e América Latina; 2. Estados Unidos; 3. Outros países / regiões. Seja como for, o formato adotado em 2010 não permitia a realização do teste ANOVA, uma vez que temos uma variável dependente nominal. Todavia, realizando um teste CHI-SQUARE obtemos um $\mathrm{p}$ valor de 0,024 , indicando que as opiniões dos deputados sobre $\mathrm{o}$ interesse que o governo deveria ter em formular sua política externa variam significativamente entre os blocos analisados.

Ao analisarmos a Tabela 3, podemos observar que os resultados para esta questão são coerentes com aqueles encontrados no survey de 2005. Novamente o bloco do PT inclina-se de forma nítida para a América Latina: $75 \%$ dos deputados entrevistados optaram por assinalar a região como prioritária, ao passo que apenas $6,1 \%$ preferiram marcar os EUA. No bloco do PSDB as opiniões encontram-se mais divididas e o percentual dos que assinalaram a América Latina é apenas um pouco superior aos que preferiram apontar os norte-americanos como parceiros preferenciais. Tal como em 2005, o bloco PMDB/PP/PTB / PR colocou-se em posição intermediária.

Tabela 3

Opinião dos Deputados sobre os Países em que o Governo Deveria Ter Interesse em Formular sua Política Externa

\begin{tabular}{lcccc}
\hline Países & \multicolumn{3}{c}{ Blocos Partidários } & \multirow{2}{*}{ Total } \\
\cline { 2 - 4 } & PT & PSDB & PMDB & \\
\hline América Latina & $75,8 \%$ & $40,6 \%$ & $57,7 \%$ & $58,1 \%$ \\
Estados Unidos & $6,1 \%$ & $31,3 \%$ & $13,5 \%$ & $16,2 \%$ \\
Outros & $18,2 \%$ & $28,1 \%$ & $28,8 \%$ & $25,6 \%$ \\
& $100,0 \%$ & $100,0 \%$ & $100,0 \%$ & $100,0 \%$ \\
\hline
\end{tabular}

Elaboração dos autores.

No survey de 2010 foi introduzida uma pergunta que diz respeito à avaliação dos líderes políticos internacionais, incluindo o ex-presidente Lula:

- EXT. Como o(a) Sr(a) avalia, em termos gerais, cada um dos líderes políticos que vou listar? Utilize a escala a seguir, onde 1 significa "uma avaliação muito negativa" e 10, "muito positiva". 
- EXT7. Lula

- EXT8. Moralez

- EXT9. Chávez ${ }^{26}$

Como mostra a Tabela 4, existe diferença significativa entre os blocos, com o do PMDB situando-se em posição intermediária nas três questões. A diferença é que, quando Evo Morales e Hugo Chávez são avaliados, o contraste se verifica entre o bloco PT/PSB/PDT/PC do B e os outros dois. Quando é Lula o avaliado, as posições são significativamente diferentes quando os blocos são comparados de forma pareada.

Tabela 4

Avaliação de Líderes Políticos Internacionais

\begin{tabular}{|c|c|c|c|c|c|c|}
\hline \multirow[t]{2}{*}{ Survey } & \multirow[t]{2}{*}{ Variável } & \multirow[t]{2}{*}{$\mathbf{F}$} & \multirow{2}{*}{$\begin{array}{c}\text { Avaliação do lí- } \\
\text { der político }\end{array}$} & \multicolumn{3}{|c|}{ TUKEY'S HSD } \\
\hline & & & & $P T \backslash P S D B$ & $\mathrm{PT} \backslash \mathrm{PMDB}$ & $P M D B \backslash P S D B$ \\
\hline \multirow[t]{3}{*}{2010} & EXT7 & $* * 0$ & $\mathrm{PT}>\mathrm{PMDB}>\mathrm{PSDB}$ & ${ }^{* *} 0$ & ${ }^{* *} 0$ & ${ }^{* *} 0$ \\
\hline & EXT8 & $* * 0$ & $\mathrm{PT}>\mathrm{PMDB}>\mathrm{PSDB}$ & $* * 0$ & $* * 0$ & 0,10 \\
\hline & EXT9 & $* * 0$ & $\mathrm{PT}>\mathrm{PMDB}>\mathrm{PSDB}$ & $* * 0$ & $* * 0$ & 0,291 \\
\hline
\end{tabular}

Elaboração dos autores.

As diferenças, como mostram os escores padronizados, são bastante expressivas. Os parlamentares dos blocos do PMDB e do PSDB expressam rejeição semelhante a Evo e Chávez, ao mesmo tempo que se distanciam do outro bloco. Quando é Lula o avaliado, o bloco do PMDB revela uma avaliação positiva, ainda que claramente inferior à apresentada pelo do PT.

Em ambos os surveys os deputados foram questionados a respeito de temas considerados polêmicos. Em 2005, os assuntos foram o divórcio e o aborto. Em 2010 não foi utilizada a questão sobre o divórcio. Em seu lugar se procurou verificar a opinião dos deputados sobre a união civil de pessoas do mesmo sexo. Como para 2005 não foram verificadas diferenças significativas entre as médias dos blocos, apresentamos apenas os resultados para 2010. As perguntas utilizadas possuíam as seguintes formulações:

- VAL1. Indique na seguinte escala sua opinião sobre a descriminalização do aborto. 1. Contrário. 10. A favor.

- VAL2. Mudando de tema, com que firmeza o(a) Sr(a) aprova ou desaprova que casais do mesmo sexo possam ter direito a casar-se? Por 
favor, utilize esta escala que vai de 1 a 10, na qual 1 significa que "desaprova firmemente" e 10 que "aprova firmemente".

A Tabela 5 e o Gráfico 4 mostram que somente o bloco do PT se distingue claramente dos demais, enquanto os deputados dos blocos do PSDB e do PMDB apresentam opiniões muito próximas. No que se refere ao tema do aborto, o bloco PSDB/DEM/PPS é o mais conservador, mas quando o tema é a união de pessoas do mesmo sexo é o bloco do PMDB que se mostra mais refratário.

Tabela 5

Opinião sobre Temas Polêmicos: Aborto e União de Pessoas do mesmo Sexo

\begin{tabular}{lcccccc}
\hline Survey & Variável & \multirow{2}{*}{ F } & Conservadorismo & \multicolumn{3}{c}{ TUKEY'S HSD } \\
\cline { 5 - 7 } & & & & PT $\backslash$ PSDB & PT $\backslash$ PMDB & PMDB $\backslash$ PSDB \\
\hline 2010 & VAL1 & $* * 0$ & PSDB $>$ PMDB $>$ PT & ${ }^{* *} 0$ & $* * 0$ & 0,43 \\
\hline & VAL2 & $* * 0$ & PMBD $>$ PSDB $>$ PT & ${ }^{* *} 0$ & $* * 0$ & 0,94 \\
\hline
\end{tabular}

Elaboração dos autores.

Resta analisar as respostas às questões sobre o sistema eleitoral e as relações entre os deputados e seus partidos. No que se refere ao primeiro ponto, em ambos os surveys solicitou-se aos deputados que escolhessem entre (a) um sistema de tipo majoritário e outro de tipo proporcional, e (b) um sistema de voto personalizado e outro de lista fechada. Em todos os casos foi utilizada uma escala de 1 a 10 para as respostas. No survey aplicado em 2010, os deputados foram perguntados, ainda, sobre o tipo de financiamento a ser adotado nas campanhas eleitorais e

Gráfico 3

Escores Padronizados da Avaliação de Líderes Políticos Internacionais

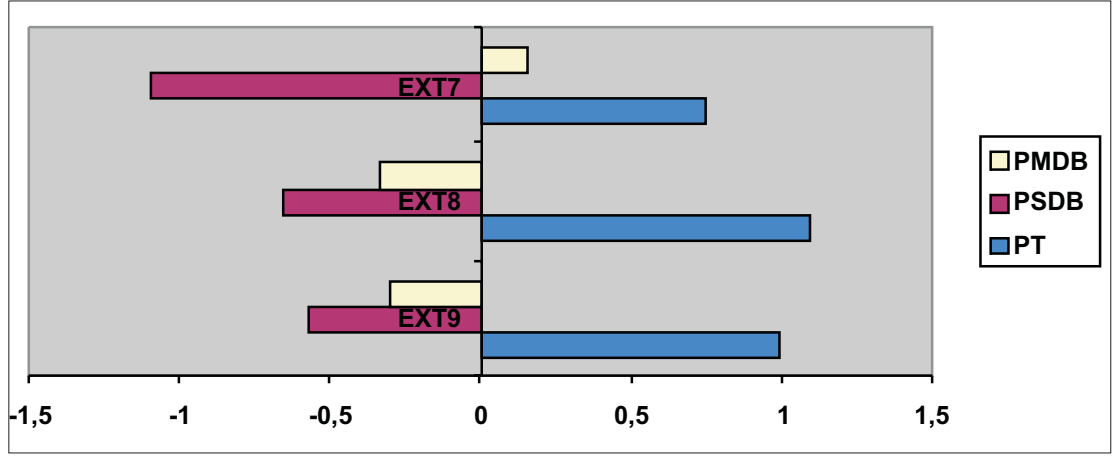

Elaboração dos autores. 
Gráfico 4

Escores Padronizados das Opiniões dos Deputados sobre Temas Polêmicos:

Aborto e União de Pessoas do mesmo Sexo

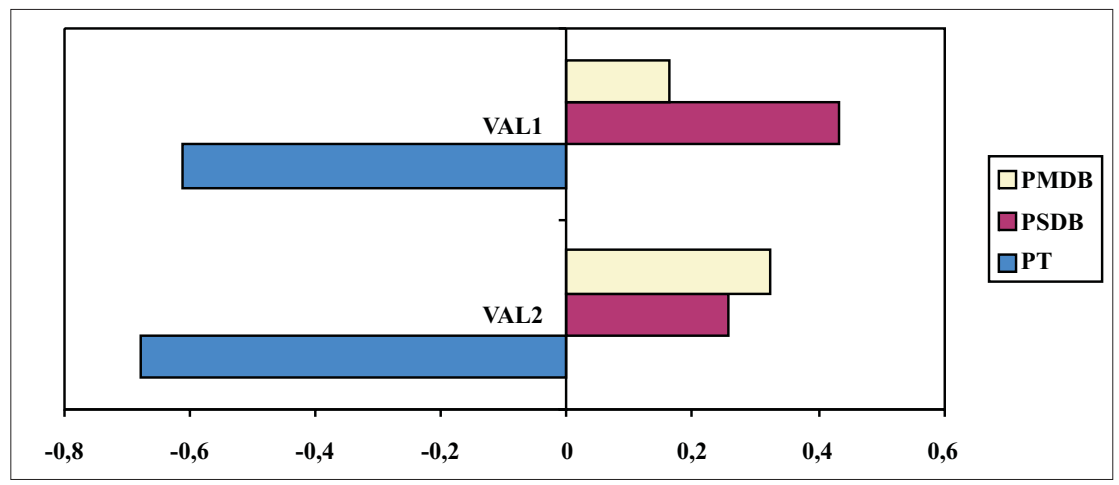

Elaboração dos autores.

sobre a realização de coligações para as eleições proporcionais. No que se refere ao segundo ponto, a relação com os partidos, procurou-se verificar, nos dois surveys, a opinião dos deputados sobre (1) a disciplina partidária, (2) a possibilidade de expulsão de um membro da bancada, (3) a troca de legenda no curso do mandato, e (4) a posição adotada no caso de conflito entre as posições do partido e os interesses do estado. Analisamos os resultados em dois momentos. Inicialmente nos voltamos para as questões nas quais foi possível realizar o teste de médias as relativas ao sistema eleitoral e à expulsão de um membro da bancada. Posteriormente nos debruçamos sobre as demais; aquelas em que o nível de mensuração adotado foi nominal e as categorias/respostas não podiam ser ordenadas, inviabilizando a utilização do ANOVA.

As questões nas quais foi possível realizar o teste de médias tiveram a seguinte formulação:

- SE1. Pensando nas eleições para a Câmara dos Deputados, e considerando a escala a seguir, em que 1 significa "o apoio a um sistema de voto personalizado" e 10, "o apoio a um sistema de lista fechada", diga qual o(a) Sr(a) acredita ser a posição ideal para o Brasil.

- SEI2. Pensando nas eleições para a Câmara dos Deputados, e considerando a escala a seguir, em que 1 significa "o apoio a um sistema majoritário" e 10, "o apoio a um sistema proporcional", diga qual o(a) Sr(a) acredita ser a posição ideal para o Brasil. 
- PART1. Agora gostaria de saber em que medida o(a) Sr(a) concorda com a afirmação a seguir: "Um partido político deveria expulsar um parlamentar quando ele vota contra as determinações políticas de seu partido". 1. Discorda. 2. Concorda Pouco. 3. Concorda mais ou menos. 4. Concorda muito.

Na Tabela 6 e no Gráfico 5, relacionamos aquelas questões nas quais o ANOVA mostrou haver diferença estatisticamente significante entre as médias dos blocos. Pela primeira vez, o bloco do PSDB aproxima-se do bloco do PT ao mesmo tempo em que este revela diferença significativa em todas as questões face ao bloco do PMDB.

Tabela 6

Questões Relativas ao Sistema Eleitoral e à Relação entre Deputados e Partidos

\begin{tabular}{lcccccc}
\hline Survey & Variável & F & Ordenamento & \multicolumn{3}{c}{ TUKEY'S HSD } \\
\cline { 4 - 6 } & & & PT $\backslash$ PSDB & PT $\backslash$ PMDB & PMDB $\backslash$ PSDB \\
\hline 2005 & SE1 & $* * 0$ & PSDB $>$ PT $>$ PMDB & 0,49 & ${ }^{*} 0,05$ & $* * 0$ \\
\hline 2010 & SEI2 & ${ }^{* *} 0,01$ & PT $>$ PSDB $>$ PMDB & 0,37 & ${ }^{* *} 0,01$ & 0,355 \\
\hline & Part1 & ${ }^{*} 0,02$ & PT $>$ PSDB $>$ PMDB & 0,84 & $* 0,03$ & 0,138 \\
\hline
\end{tabular}

Elaboração dos autores.

${ }^{*} \mathrm{p}<0,05 ;{ }^{* *} \mathrm{p}<0,01$

Em 2005 os deputados do PSDB, DEM e PPS se mostraram mais favoráveis à adoção de um sistema de lista fechada (SE1) do que aqueles pertencentes ao bloco do PT. Os deputados do bloco do PMDB, por sua vez, se inclinavam mais claramente para um sistema de voto personalizado. Em 2010 as diferenças entre as médias dos blocos no que se refere a esta questão não se revelaram significativas, mas vale mencionar que os deputados do bloco PT e do PSDB alternaram suas posições deixando o bloco do PMDB em terceiro lugar ${ }^{27}$.

Em 2010 os deputados do PMDB, PP, PTB e PR se declararam significativamente mais propensos a apoiar um sistema de tipo majoritário do que os deputados do bloco do PT - estes por sua vez não se distinguiam de forma significativa daqueles pertencentes ao bloco do PSDB $^{28}$. Embora o ordenamento dos blocos tivesse sido o mesmo, o survey de 2005 não revelou diferença significativa entre as médias no que se refere a esta questão.

Finalmente, em 2010 foram também os deputados do bloco do PMDB os que com mais ênfase discordavam da expulsão de um deputado "in- 
Gráfico 5

Escores Padronizados das Questões Relativas ao Sistema Eleitoral e

à Relação entre Deputados e Partidos

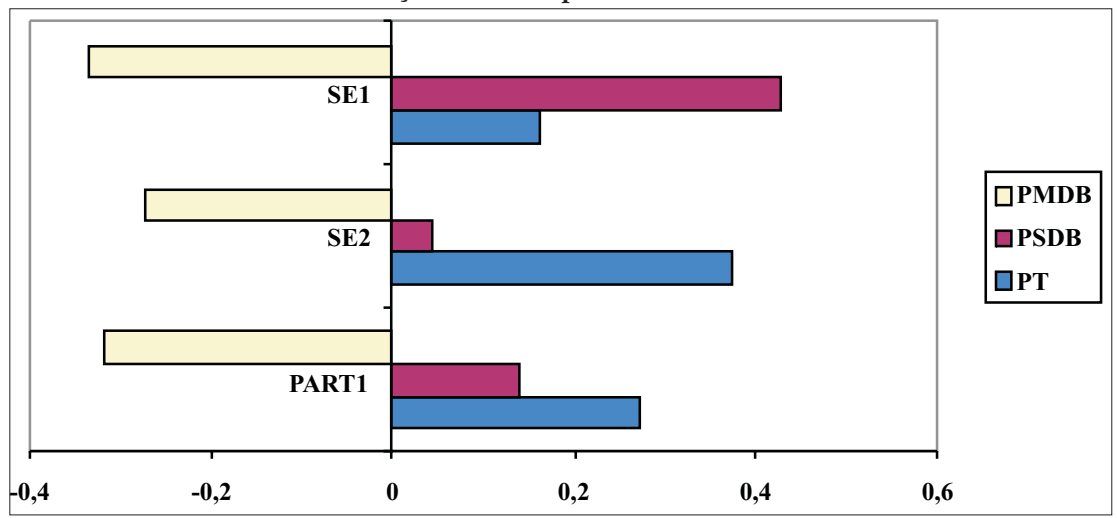

Elaboração dos autores.

fiel". A diferença, novamente, é mais expressiva quando as respostas são comparadas àquelas dadas pelos deputados do bloco do PT. Em 2005 a questão não revelou diferença significativa entre as médias, mas a posição relativa dos blocos foi a mesma daquela apresentada na Tabela $6^{29}$.

Conforme relatado acima, algumas das questões sobre o sistema eleitoral e as relações entre deputados e partidos foram formuladas em formatos que impossibilitavam a realização do teste ANOVA. Nesses casos, optamos por realizar o teste CHI-SQUARE para verificar se as opiniões dos deputados diferiam significativamente entre os blocos analisados. Na Tabela 7 apresentamos os resultados, optando por manter o conjunto das questões analisadas.

Em todas as questões analisadas nos dois surveys o ordenamento dos blocos é o mesmo e são os deputados pertencentes ao bloco $\mathrm{PMDB} / \mathrm{PP} / \mathrm{PTB} / \mathrm{PR}$ os que adotam posições que podemos caracterizar como menos partidárias e mais individualistas. Tal ordenamento é consistente com o quadro revelado na Tabela 6. Dentre as questões analisadas apenas a que se referia à mudança de partido durante o mandato não revelou diferença significativa entre os blocos em pelo menos um dos períodos analisados. No que se refere à existência de conflitos entre as posições do partido e os interesses do estado, a diferença entre os blocos revelou-se significativa para 2005, ainda que não para 2010. Nos dois períodos, a maior distância observada é aquela entre os depu- 
Estrutura da Competição pela Presidência e Consolidação do Sistema Partidário...

Tabela 7

Posições dos Deputados a respeito de Questões Relativas ao Sistema Eleitoral e à Relação com seus Partidos

\begin{tabular}{c|l|c|c|c|c}
\hline Ano & \multicolumn{1}{|c|}{ Questão } & $\begin{array}{c}\text { Bloco } \\
\text { PT }\end{array}$ & $\begin{array}{c}\text { Bloco } \\
\text { PSDB }\end{array}$ & $\begin{array}{c}\text { Bloco } \\
\text { PMDB }\end{array}$ & $\begin{array}{c}\text { Chi- } \\
\text { square }\end{array}$ \\
\hline \multirow{2}{*}{$\mathbf{2 0 0 5}$} & $\begin{array}{l}\text { Deputados favoráveis a que se renuncie à cadei- } \\
\text { ra em caso de troca de partido }\end{array}$ & $74,2 \%$ & $63,6 \%$ & $57,6 \%$ & 0,30 \\
\hline & $\begin{array}{l}\text { Deputados que declaram votar com o partido } \\
\text { em caso de conflito com os interesses do estado }\end{array}$ & $50 \%$ & $32,1 \%$ & $8,9 \%$ & $* * 0$ \\
\hline \multirow{2}{*}{$\mathbf{2 0 1 0}$} & $\begin{array}{l}\text { Deputados favoráveis a que se renuncie à cadei- } \\
\text { ra em caso de troca de partido }\end{array}$ & $64,5 \%$ & $62,3 \%$ & $46,0 \%$ & 0,17 \\
\hline & $\begin{array}{l}\text { Deputados favoráveis a que se exija a disciplina } \\
\text { peputados que declaram votar com o partido } \\
\text { pem caso de conflito com os interesses do estado }\end{array}$ & $36,4 \%$ & $21,9 \%$ & $17,0 \%$ & 0,14 \\
\hline & $\begin{array}{l}\text { Deputados favoráveis à adoção de financiamen- } \\
\text { to público exclusivo }\end{array}$ & $65,7 \%$ & $61,3 \%$ & $37,3 \%$ & $* * 0$ \\
\hline & $\begin{array}{l}\text { Deputados favoráveis à proibição de coligações } \\
\text { nas eleições proporcionais }\end{array}$ & $51,4 \%$ & $54,5 \%$ & $44,2 \%$ & $* 0,03$ \\
\hline
\end{tabular}

Elaboração dos autores.

${ }^{*} \mathrm{p}<0,05 ;{ }^{* *} \mathrm{p}<0,01$

tados do bloco do PT e os pertencentes ao bloco do PMDB. Em 2010 o percentual de deputados do bloco do PMDB que julgava necessário exigir disciplina sempre que o partido houvesse definido posição era significativamente menor do que o verificado para os demais partidos analisados $^{30}$. A posição do bloco é consistente com a postura mais flexível de seus deputados quando perguntados sobre a possibilidade de expulsão de um membro da bancada que votasse contra as orientações do partido.

No que se refere ao sistema eleitoral, o conjunto de questões analisadas nas Tabelas 6 e 7 deixa claro que os deputados do bloco do PMDB são (1) mais propensos a apoiar um sistema de tipo majoritário, mas (2) diante de um sistema de representação proporcional (3) possuem forte preferência pela lista aberta, (4) resistem à adoção de um financiamento público exclusivo e são (5) amplamente favoráveis à manutenção das coligações para as eleições proporcionais. No extremo oposto, em todas as questões, estão os deputados do bloco do PT, repetindo o que se observa quando as perguntas se referem à relação entre os deputados e seus partidos. Em uma frase, os deputados dos dois blocos possuem opiniões significativamente distintas quando se trata de valorizar 
os partidos políticos, seja na relação com os seus membros, seja nas escolhas sobre o sistema eleitoral.

Por fim, tratamos de verificar se o conjunto de questões aqui analisadas poderia ser correlacionado com duas variáveis: o autoposicionamento dos deputados em uma escala ideológica e frente ao governo Lula. Os resultados mostram, por um lado, que não existe correlação entre o fato de o deputado se declarar de oposição ou governo e as respostas dadas a nenhuma das questões examinadas. O resultado era esperado, dado que, como visto nesta seção, a média das preferências dos deputados pertencentes ao bloco do PMDB encontra-se, na maioria das vezes, mais próxima dos legisladores perfilados com a oposição do que de seus colegas de coalizão. Por outro lado, na maioria das questões, as respostas dadas possuem correlação significativa com a maneira como os deputados se posicionam no contínuo esquerda/direita: deputados situados à esquerda são mais favoráveis à presença do estado na economia, preferem maior atuação estatal no controle de serviços públicos e recursos naturais, são mais refratários a uma aproximação com os EUA na política externa, valorizam a atuação de lideranças como Evo Morales e Hugo Chávez, apoiam a união civil de pessoas do mesmo sexo, são mais favoráveis à descriminalização do aborto, se dizem mais propensos a votar com o partido em caso de conflito com interesses de seu estado e menos tolerantes com aqueles que contrariam as posições partidárias ${ }^{31}$.

Isso significa que a variável ideologia deve ser levada em conta se pretendemos entender a estrutura assumida pela competição no sistema partidário brasileiro. Ainda que a distância entre esquerda e direita no Congresso tenha diminuído desde os anos 1980 (Lucas e Samuels, 2010 e 2011; Zucco, 2011), o fato é que os blocos capitaneados pelo PT e pelo PSDB não se distinguem apenas porque dois corpos não podem ocupar o mesmo espaço - no caso, a cadeira da Presidência. Pelo que mostram nossos dados, seus deputados divergem a respeito de questões relevantes e tal divergência guarda relação com a posição assumida na escala esquerda/direita. Ademais, os dados são consistentes com o que ocorre no mundo real: sem levar em conta a clivagem ideológica não seria possível entender por que o então PFL não seguiu o caminho do PP e aderiu ao governo petista, ou por que o PPS deslocou-se para a oposição, ou mesmo por que a bancada do PDT continuou, de forma majoritária, votando com o governo mesmo estando fora da coalizão na maior parte do primeiro mandato de Lula. Por outro lado, a cliva- 
gem ideológica não tem nada a dizer sobre as motivações de PMDB, PP, PTB e PR para participar da coalizão constituída pelo PT. No caso destas legendas trata-se, pura e simplesmente, de situar-se ao lado de quem ocupa a cadeira presidencial - um comportamento que certamente pode ser tipificado como incoerente para um analista à procura de consistência programática, mas que é perfeitamente previsível e compatível com a estrutura de competição assumida pelo sistema partidário brasileiro.

\section{CONCLUSÃO}

Este artigo retoma o debate sobre o grau de consolidação do sistema partidário brasileiro. Do ponto de vista analítico adotamos um caminho distinto do costumeiro: ao invés de utilizarmos o conceito de institucionalização, amplamente disseminado a partir da abordagem de Mainwaring e Scully, preferimos nos apoiar em Mair $(1996,2006)$ e seguir a sugestão de que o coração de um sistema partidário é constituído pela estrutura da competição pelo controle do Poder Executivo nacional. A nosso ver, tal opção possibilita destacar o que realmente provocou uma mudança no sistema partidário brasileiro nas últimas duas décadas: o surgimento de um determinado padrão de interação entre os partidos na competição pela Presidência da República.

O caso brasileiro seria expressivo de uma situação em que um quadro de interações inicialmente dotado de baixa coerência começa a tomar forma e adquire estrutura. Entre 1982 e 1994, o quadro partidário brasileiro seria mais bem caracterizado pela fluidez e pela quase ausência de características sistêmicas, a ponto de uma coalizão que controlava as duas casas no Congresso e todos os governos estaduais em 1987 amealhar apenas 5,6\% dos votos presidenciais dois anos depois. A superação deste quadro, com a redefinição do espaço da competição, de seus protagonistas e suas estratégias, iria representar o fator decisivo para os rumos do sistema partidário brasileiro. A competição pela Presidência da República passaria a ser estruturada em torno de duas coalizões ideologicamente distintas, inaugurando uma dinâmica com impacto sobre as escolhas de cada um dos partidos relevantes e sobre o grau de consolidação do sistema partidário.

A partir desta perspectiva procuramos mostrar que a tese de que o sistema partidário brasileiro encontra-se hoje mais incoerente do que antes é equivocada. Dialogando com Lucas e Kevin (2010, 2011), argu- 
mentamos que, quando se analisa a questão sob a ótica da estrutura da competição pela Presidência da República, o fato de que PSDB e DEM tenham se tornado "indistinguíveis" perde a relevância. Destacamos, ainda, que antes de se computar o fenômeno da "convergência ao centro" como evidência das mazelas do sistema, é preciso considerar tal movimento como parte da estratégia dos partidos na competição pelo governo e, ademais, como algo corriqueiro no âmbito das democracias contemporâneas. E discordamos da afirmação de que a disjuntiva "PT versus o resto" seja o que melhor caracteriza o sistema partidário brasileiro. É certo que o PT possui traços que o distinguem dos demais partidos brasileiros. Mas isso não significa, como querem os autores, que estejamos diante de "um sistema de dois blocos, com o PT à esquerda e PSDB/PMDB/PFL no centro" (2011:84).

A nosso ver, o cenário é um tanto distinto uma vez que a estrutura assumida pela competição em torno da Presidência da República permite identificar três, e não dois, blocos distintos no sistema partidário brasileiro. Tal como em muitos sistemas partidários nas democracias ocidentais, aqui a disputa se dá entre as posições de centro-direita e centro-esquerda. O que torna peculiar o caso brasileiro é a existência de um bloco de partidos entre os dois polos que balizam o jogo. Valendo-se das bancadas eleitas para o Congresso, PMDB, PP, PTB e PR têm em comum a disposição e a possibilidade de aderir ao governo de plantão. Isso permite caracterizar o sistema partidário brasileiro como dotado de uma estrutura aberta de competição, na qual os dois polos tendem a se alternar, mas na forma de coalizões flexíveis, nas quais o número de participantes bem como o espaço ocupado por eles em uma escala esquerda/direita não se encontra definido de antemão.

O posicionamento do bloco do PMDB poderia ser visto como incoerente para um analista à procura de consistência programática. Mas se mudarmos o foco iremos perceber que a oscilação destes partidos entre os dois outros blocos nada tem de surpreendente. Dito de outra forma, o movimento é perfeitamente compatível, e previsível, desde que se entenda como os partidos passaram a interagir na disputa pela Presidência da República. Faz sentido, portanto, distinguir o bloco do PMDB. Trata-se de um conjunto de partidos que possui um comportamento diferente dos outros dois - seus componentes simplesmente aderem a qualquer governo; possuem, por assim dizer, uma vocação governista "à flor da pele". Vocação facilitada pelo fato de que, graças ao aninhamento das eleições e ao caráter coalizacional do presidencia- 
lismo, existem pelos menos três estratégias possíveis de serem seguidas se um determinado partido deseja participar do jogo presidencial: lançar candidato à eleição propriamente dita, concentrar esforços em candidatos competitivos nos estados ou, na pior das hipóteses, fazer as alianças necessárias com o objetivo de eleger uma bancada de porte médio no Congresso.

A análise dos surveys realizados na Câmara dos Deputados, por sua vez, permitiu verificar, com base nas percepções dos deputados, o que distingue os três blocos aqui referidos. Neste sentido, ficou claro que: (a) existe uma diferenciação de caráter ideológico entre os blocos do PT e do PSDB no que se refere ao papel do estado na economia, à política externa e a opiniões sobre questões como aborto e união de pessoas do mesmo sexo; (b) a média das opiniões dos deputados do bloco PMDB/PTB/PP/PR aproxima-se mais do bloco PSDB/DEM/PPS do que do PT e seus aliados na maioria das questões analisadas - as exceções ficaram por conta da avaliação do ex-presidente Lula e da importância conferida à América Latina na política externa - deixando claro que existe uma distinção entre o comportamento estratégico, ditado pelo formato que a competição assumiu, e as preferências dos referidos deputados; e (c) nas questões relativas à reforma política e à relação dos deputados com os partidos, a maior distância observada é aquela entre o bloco do PT e o do PMDB ao passo que as opiniões dos deputados do PSDB, DEM e PPS aproximam-se do primeiro.

Isso nos permite dizer que a ocorrência de uma convergência ao centro no sistema partidário brasileiro não se deu a ponto de anular a importância da variável ideologia para que se possa entender a estrutura assumida pela competição no sistema partidário brasileiro. Os blocos capitaneados pelo PT e pelo PSDB não se distinguem apenas porque dois corpos não podem ocupar o mesmo espaço - no caso, a cadeira da Presidência. Fosse assim, o antigo PFL poderia ter ensaiado um movimento na direção da mega coalizão de apoio a Lula. Por outro lado, a clivagem ideológica não tem nada a dizer sobre as motivações de PMDB, PP, PTB e PR para participar da coalizão constituída pelo PT. No caso destas legendas trata-se, pura e simplesmente, de situar-se ao lado de quem ocupa a cadeira presidencial.

Eleger a movimentação do bloco do PMDB em direção ao governo Lula como evidência inconteste de que o sistema partidário tornou-se mais incoerente é esquecer que os partidos, nas democracias, se movem por 
votos, cargos e políticas (Mueller e Strom, 1999). Com base em que deveríamos esperar que os partidos brasileiros fizessem suas escolhas prioritariamente motivados pela política? Até certo ponto, alguns podem fazê-lo; para outros, no entanto, a questão não está colocada. Programas e ideologia à parte, a opção feita pelo bloco do PMDB "revela" o que já sabemos - que a maioria dos partidos brasileiros tem dificuldade em sobreviver sem os preciosos recursos provenientes do governo federal.

A posição ocupada pelo bloco do PMDB adquire relevância, é evidente, pelo fato de que os partidos que o compõem terem participado da base parlamentar de apoio a Lula em seus dois mandatos, não obstante a distância verificada entre as preferências de seus deputados e aquelas do partido formador da coalizão, o PT. Se para o governo Lula o ingresso dos partidos de centro e direita no governo foi uma solução, foi também fonte de problemas: como lembra Magna Inácio (2009:354), "coalizões compostas por partidos que não ocupam posições contíguas no espectro ideológico podem resultar em situações mais complexas de barganha, na medida em que os membros mais distantes podem apoiar propostas dos partidos de oposição que lhes são próximos". Complexidade que se torna ainda mais evidente quando se sabe que os deputados do bloco do PMDB se mostraram mais propensos a aceitar que o deputado vote livremente, mesmo que o partido tenha definido posição, mais refratários a que o partido adote medidas contra os "infiéis", menos dispostos a votar com o partido quando houver conflito de interesse com o estado de origem e, como não poderia deixar de ser, mais inclinados a manter um sistema de voto personalizado.

Por fim, duas observações. Em primeiro lugar não devemos ir muito longe ao elogiar o atual estágio do sistema partidário brasileiro. Nosso sistema e nossos partidos emitem sinais contraditórios. A dinâmica adquirida na competição pela Presidência representou um importante ganho em termos de estruturação do sistema, mas não teve o poder de diminuir o nível de fragmentação encontrado no Congresso ou nas Assembleias Legislativas, de fazer com que os partidos, de um modo geral, adquirissem raízes na sociedade ou incrementassem seu grau de legitimidade perante o eleitorado, ou ainda, de impedir que parcela considerável dos políticos continue a considerar o pertencimento a esta ou àquela legenda como uma escolha meramente circunstancial, como acabou de nos mostrar o sucesso da iniciativa de Gilberto Kassab na criação de seu PSD. Aqui cabe simplesmente voltar à contribuição 
de Luna e Altman (2011): ganhamos musculatura quando se analisa a dimensão da competição eleitoral, mas não há nada de novo na relação entre os partidos e a sociedade.

Em segundo lugar, não estamos diante de um quadro estanque. Como já ressaltado, os dois blocos em torno dos quais gira o jogo vivem tensões específicas. No bloco do PSDB, submetido a um longo tempo de ausência do governo federal, o acelerado declínio do DEM e a falta de perspectivas do PPS fazem com que a fusão entre os partidos se torne uma alternativa plausível. O bloco do PT se vê às voltas com o crescimento do PSB. Neste texto argumentamos que o Brasil pode ser caracterizado como um país no qual a competição adquiriu uma estrutura que não tinha. Isso não significa que tal estrutura não possa ser substituída por outra. Seja como for, se o núcleo de um sistema partidário remete à estrutura da competição pelo controle do Executivo, o sistema partidário brasileiro deixou, já de algum tempo, de poder ser caracterizado como caótico ou incipiente.

(Recebido para publicação em novembro de 2011)

(Reapresentado em março de 2012) (Aprovado para publicação em abril de 2012) 


\section{NOTAS}

1. A lista é extensa. A respeito do comportamento dos partidos brasileiros no plenário da Câmara e do Senado ver, entre outros, Nicolau (2000), Santos (2003), Pereira e Muller (2003), Inácio (2006 e 2009), Miranda (2009), Neiva (2011).

2. Neste artigo retomamos e desenvolvemos o argumento apresentado pelo autor.

3. Cabe ressaltar que, no trabalho de 2008 , os autores deixam claro que a análise era "cartográfica", ou seja, totalmente baseada nas percepções dos deputados sem preocupação com o significado substantivo das posições ideológicas assumidas ou com o impacto das mesmas sobre o comportamento legislativo.

4. O termo bloco será utilizado neste artigo como querendo indicar conjuntos de partidos que podem ser diferenciados com base na estrutura da competição em torno da Presidência da República e não necessariamente como designando partidos que possuem um comportamento coerente e definem suas estratégias de forma concertadacomo seria o caso de um bloco parlamentar. PMDB, PP, PTB e PR certamente não poderiam ser caracterizados como um bloco caso adotássemos esta segunda perspectiva, mas o que importa aqui é a disposição, comum a todos eles e distinta dos demais, em partilhar o governo com qualquer coligação que assuma a Presidência.

5. Nas duas ocasiões trabalhamos com uma amostra aleatória, estratificada por partido. Foram entrevistados 134 deputados(as) entre agosto e dezembro de 2005 e 127 entre março e julho de 2010. As entrevistas foram presenciais e apenas o(a) deputado(a) participava da mesma. O Anexo 1 discrimina o número de deputados entrevistados por partido nas duas rodadas do survey comparado com o tamanho das bancadas. No banco de dados, as diferenças eventualmente existentes entre o tamanho das bancadas de alguns partidos e o percentual de deputados entrevistados foram corrigidas por um mecanismo de ponderação. A pesquisa conduzida pelo Centro de Estudos Legislativos do Departamento de Ciência Política da UFMG faz parte do projeto “Representação Política e Qualidade da Democracia: um estudo das elites parlamentares da América Latina", coordenado por pesquisadores da Universidade de Salamanca. Desde 2005 o CEL-DCP tem se responsabilizado pela realização do módulo Brasil do Projeto. O questionário aplicado possui um eixo comum a todos os países onde o estudo é conduzido e algumas questões especificamente formuladas para o Brasil. Aproveitamos a oportunidade para agradecer às demais coordenadoras do Projeto no Brasil - Magna Inácio, Fátima Anastasia e Mônica Mata Machado de Castro - bem como a todos os estudantes que se envolveram na realização das entrevistas. Nas duas ocasiões a pesquisa contou com o financiamento do CNPq e da Fapemig.

6. O privilégio dado aos partidos de massa torna difícil também a análise do caso norte-americano; afinal, nos EUA a existência de um "sistema natural de canalização" prescindiu da emergência de partidos daquele tipo.

7. Além destas, o trabalho inicial propunha que se levasse em conta a legitimidade conferida pelos atores políticos aos partidos e a prevalência das organizações partidárias sobre os interesses dos líderes.

8. O caso da Venezuela permite lembrar que a contribuição dos autores auxilia no enfrentamento da já mencionada questão da mudança. A débâcle venezuelana poderia ser explicada como um caso de trade off entre o controle exercido pelos partidos até o 
início dos anos 1990 e o sentimento nutrido pelos eleitores em relação à elite política um acaso de sistema estável no que se refere à competição eleitoral mas em acelerado processo de esgarçamento de suas relações com a sociedade. Este ponto foi desenvolvido também por Anastasia, Melo e Santos (2004).

9. Também merece comentário a observação feita por Mainwaring e Torcal (2005:268; 2006) no sentido de que nos sistemas partidários das novas democracias deve-se prestar atenção à existência de vínculos não programáticos e não ideológicos que, não obstante, servem como orientação aos eleitores e contribuem para a conformação de um cenário eleitoral estável. Tais vínculos poderiam ser de ordem clientelista, personalista ou mesmo tradicional. Em qualquer dos casos os laços ideológicos / programáticos, se existentes, serão frágeis, mas isso não significa que o sistema partidário funcione de forma volátil. Voltando a Luna e Altman, situações como estas não apontariam para um sistema completamente institucionalizado, uma vez que os vínculos de ordem clientelista, personalista ou tradicional tendem a ser menos duradouros do que aqueles adquiridos nos processos de socialização que possibilitam a identificação do eleitor com determinado partido.

10. O quadro pode se complicar um pouco mais se lembrarmos que, pelo menos até 2006, parte da volatilidade medida no Brasil devia-se não ao fato de que o eleitor tivesse mudado de partido entre uma eleição e outra, mas ao fato de que ele havia acompanhado o seu candidato que, isso sim, trocara de legenda! Dados apresentados por Melo (2004) mostram que os estados que possuíam os maiores índices de volatilidade para a Câmara dos Deputados até 2002 eram também os que apresentavam os maiores percentuais de deputados que haviam trocado de partido entre uma eleição e outra.

11. Cálculo feito pelos autores.

12. Para uma distinção entre um "quadro de partidos" e um "sistema partidário", ver Bardi e Mair (2008). Na trilha de Sartori (1976), os autores retomam a discussão sobre a necessidade de que exista um padrão de interação entre os partidos para que se possa falar de sistema.

13. PDT e PCB/PPS apresentaram candidatos próprios em três eleições, mas nem sempre de forma competitiva. PMDB e PDS/PP lançaram candidatos próprios em 1989 e 1994, mas apenas o segundo logrou mostrar-se competitivo, com Maluf, na primeira eleição. O PV estreou em 1989 e voltou em 2010 com Marina Silva. Finalmente, DEM, PSB, PTB e PL/PR lançaram candidato uma vez cada.

14. A consequência foi um pífio desempenho nos estados. Ainda que entre 1986 e 1998 o PT tenha sido o partido que mais lançou candidatos aos governos estaduais, em apenas três ocasiões logrou eleger o governador. Somente a clara prevalência de uma estratégia de afirmação nacional pode explicar o fato de que o PT, sem chance de vitória em nenhum estado, tenha sido o segundo partido em número de candidaturas próprias a governador no ano de 1986 - foram 20 candidatos nas 23 disputas de então. Os dados referentes aos resultados eleitorais até 2006 mencionados neste artigo foram obtidos no Banco de Dados Eleitorais organizado por Jairo Nicolau. Para 2010 a fonte foi o TSE.

15. No período em questão o PT lançou 112 candidatos a governador e o PSDB, 81. O desempenho tucano revelou-se muito melhor: o partido chegou ao primeiro ou ao segundo lugar em 64,2\% das eleições que disputou e venceu $43 \%$ delas. O bom desem- 
penho nas disputas estaduais se revelou decisivo para a composição da bancada na Câmara dos Deputados - 60,2\% da bancada federal eleita ao longo do período veio de São Paulo, Minas Gerais, Ceará e Pará, estados onde o PSDB controla ou controlou por um bom período o Executivo estadual.

16. Ciro pertenceu ao PMDB, PSDB, PPS e PSB. Garotinho ao PDT, PSB, PMDB e PR. Entre os maiores partidos, também o PDT apresentou candidatura própria após 1994, mas Cristovam Buarque, em 2006, não era competitivo.

17. O DEM sempre utilizou de forma parcimoniosa a estratégia de lançar candidatos aos governos estaduais. Em $87,7 \%$ das vezes em que o partido disputou a cadeira, os seus candidatos chegaram ao primeiro ou segundo lugar. Venceram em 40,3\% das ocasiões. O partido nunca "marcou posição": ou tinha chances reais de vitória ou optava por uma coligação. Seu melhor desempenho foi em 1998, quando elegeu seis governadores. Em 2010 o partido lançou candidatos em apenas quatro estados.

18. Mesmo que o bloco tenha lançado mais de uma candidatura, os partidos sempre convergiram no segundo turno. A exceção foi 1994, porque não houve segundo turno. Posteriormente o PDT abandonou a coalizão de governo no primeiro mandato de Lula, sem entanto se perfilar à oposição. Manteve um padrão de votação próximo ao do PT e após 2006 reintegrou-se à base do governo.

19. O PDT manteve-se competitivo apenas no Amapá, Maranhão, Espírito Santo e Paraná. Ao que tudo indica o quadro não deve ser revertido - em 2010 o partido disputou o governo em quatro estados e não venceu em nenhum. Para o PSB o Nordeste tem lugar de destaque, com seis dos noves estados já governados pelo partido: Piauí, Ceará, Rio Grande do Norte, Paraíba, Pernambuco e Alagoas.

20. Em 1998, dividido entre lançar uma candidatura própria e apoiar FHC, o partido optou por retirar-se formalmente da disputa presidencial e concentrar suas atenções nos estados. Em 2002 o partido já havia se definido pela participação na chapa de José Serra quando o TSE impôs a verticalização das eleições. A decisão foi mantida porque não implicava conflitos: como PFL e PP haviam optado por não se alinhar formalmente a nenhum dos candidatos à Presidência, as alianças nos estados podiam ser realizadas sem maiores problemas. Em 2006, colocado entre a possibilidade de apresentar um candidato competitivo à Presidência, Anthony Garotinho, ou se ver livre para as articulações regionais, o partido, no contexto da verticalização, novamente se colocou à margem da disputa eleitoral pelo Palácio do Planalto. Em 2010, depois de o Senado haver definido, em 2007, pelo fim da verticalização, o partido pode compatibilizar interesses nacionais e estaduais, optando pela participação na chapa de Dilma Rousseff (PT) sem, no entanto, comprometer-se com o atrelamento de suas campanhas regionais à nacional.

21. Bardi e Mair (2008) retomam o ponto.

22. Na nota número 1 citamos algumas das referências. Seja como for, o diagnóstico sobre os partidos brasileiros comporta nuances. Tomando como base a pontuação média no índice de Rice, Carey (2009) sustenta que os partidos brasileiros continuam relativamente indisciplinados se adotada uma perspectiva comparada.

23. Mais precisamente, ANOVA testa a seguinte hipótese nula: $\mathrm{H} 0: \mu 1=\mu 2=\ldots=\mu$ r, isto é, se todas as médias são iguais. 
24. Para isso, subtraímos a média das opiniões de cada bloco pela média geral de cada variável e então dividimos a diferença das médias obtidas pelo desvio padrão da respectiva variável.

25. No survey os deputados eram questionados também sobre o interesse do governo brasileiro a respeito das relações com Espanha, Portugal, Japão e União Europeia. No artigo apresentamos apenas as regiões / países para os quais houve diferença significativa entre os blocos.

26. A questão solicitava ainda aos deputados que avaliassem outras lideranças como Felipe Calderón, Álvaro Uribe, José Luiz Zapatero e Barak Obama. Apresentamos aqui apenas as alternativas para as quais houve diferença significativa entre os blo$\cos$.

27. Em 2005, 48,4\% dos pertencentes ao bloco do PSDB se colocaram nas posições 8, 9 e 10, claramente favoráveis à adoção da lista fechada, enquanto $21,2 \%$ se posicionarem em 1, 2 e 3, favoráveis à lista aberta. Para os pertencentes ao bloco do PT os percentuais foram de $32,3 \%$ e 29,4\%. No bloco do PMDB o apoio à lista fechada alcançou apenas $23,7 \%$, ao passo que um sistema de voto personalizado foi preferido por $62,7 \%$. Em 2010, o apoio à lista fechada alcançou $45,1 \%$ no bloco do PT, 37,5\% no bloco do PSDB e $27,0 \%$ no terceiro bloco.

28. Em 2010 o apoio a um sistema de representação proporcional (posições 8, 9, 10) chegou a $54,4 \%$ no bloco do PT e a 38,7\% no bloco do PSDB. Apenas 23,0\% dos deputados pertencentes ao terceiro bloco declararam preferir tal sistema - em 2005 a média deste bloco havia sido de $56,0 \%$.

29. Em 2010,53,8\% dos deputados do bloco do PMDB discordavam claramente de que se pudesse expulsar um membro da bancada que votasse contra as orientações do partido. Em 2005, o bloco havia se mostrado menos condescendente com os "infiéis" e o índice havia chegado a $40 \%$. Os percentuais para os demais blocos foram semelhantes nos dois anos, sempre com o PT tendendo a adotar uma posição mais dura.

30. A pergunta sobre a disciplina foi realizada em 2005, mas a formulação adotada prejudicou os resultados. As alternativas colocadas para os deputados haviam sido: (1) Deveria se exigir sempre a disciplina de voto na bancada partidária; (2) Deveria se permitir sempre que cada deputado dê seu voto de acordo com sua própria opinião. Colocados diante de tais alternativas, a maioria dos deputados optou por declarar que sua resposta dependeria da situação. Em 2010, a alternativa número 1 teve sua redação modificada para "deveria se exigir disciplina partidária sempre que o partido houver definido posição" e os resultados foram os apresentados na Tabela 7. Mas, em que pese o problema de formulação da questão em 2005, os deputados do bloco do PMDB expressaram uma opinião menos partidária: enquanto no bloco do PT apenas 2,9\% dos respondentes assinalaram que deveria se permitir sempre que o deputado votasse de acordo com sua opinião, no bloco do PMDB o percentual chegou a $20,0 \%$.

31. No que se refere à ideologia o legislador foi convidado a se posicionar entre 1 e 10 , onde 1 representava a posição mais à esquerda. Para a outra variável a pergunta foi: “O(a) $\mathrm{Sr}$ (a) se considera do governo ou da oposição?". As opções eram 1 = governo e 2 = oposição. No Anexo 2 apresentamos os dados para as questões que mostraram correlação significativa. 


\section{REFERÊNCIAS BIBLIOGRÁFICAS}

ABRUCIO, Fernando. (1998), “O Ultra-Presidencialismo Estadual”, in R. Andrade (org.), Processo de Governo no Município e no Estado. São Paulo, EDUSP.

AMES, Barry. (2001), The Deadlock of Democracy in Brazil. Ann Arbor, MI, Michigan University Press.

AMORIM NETO, Octavio. (2000), “Gabinetes Presidenciais, Ciclos Eleitorais e Disciplina Legislativa no Brasil”. DADOS, vol. 43, no 3, pp. 479-517.

ANASTASIA, Fátima; MELO, Carlos Ranulfo e SANTOS, Fabiano. (2004), Governabilidade e Representação Política na América do Sul. Rio de Janeiro/São Paulo, Fundação Konrad-Adenauer/Ed. da UNESP.

BARDI, Luciano e MAIR, Peter. (2008), “The Parameters of Party Systems”. Party Politics vol. 14, no 2, pp. 147-166.

BARTOLINI, Stefano e MAIR, Peter. (1990), Identity, Competition and Electoral Availability: The Stabilization of European Electorates, 1885-1985. Cambridge, Cambridge University Press.

CAREY, John. (2009), Legislative Voting and Accountability. Cambridge, Cambridge University Press.

CAVAROZZI, Marcelo e CASUlLO, Esperanza. (2003), "Los Partidos Políticos en América Latina Hoy: ¿Consolidación o Crisis?", in M. Cavarozzi e J. M. A. Medina El Asedio a la Política: Los Partidos Latinoamericanos en la Era Neoliberal. Rosario, Ed. Homo Sapiens.

DALTON, Russell e WATTENBERG, Martin. (2002), Parties without Partisans: Political Changes in Advanced Industrial Democracies. New York, Oxford University Press.

FARRELL, David. (2006), "Political Parties in a Changing Campaign Environment", in R. Katz e W. Crotty (eds.), Handbook of Party Politics. London, Sage Publications.

FIGUEIREDO, Angelina e LIMONGI, Fernando. (2007), “Instituições Políticas e Governabilidade: Desempenho do Governo e Apoio Legislativo na Democracia Brasileira", in C. R. Melo e M. A. Sáez (eds.), A Democracia Brasileira: Balanço e Perspectivas para o Século 21. Belo Horizonte, Ed. UFMG.

. (2002), "Incentivos Eleitorais, Partidos e Política Orçamentária". DADOS, vol. 45, no 2, pp. 303-344.

(1999), Executivo e Legislativo na Nova Ordem Constitucional. Rio de Janeiro/São Paulo, FGV/FAPESP.

HAGOPIAN, Frances; GERVASONI, Carlos e MORAES, Juan Andrés. (2009), “From Patronage to Program: The Emergence of Party-Oriented Legislators in Brazil". Comparative Political Studies, vol. 42, no 3, pp. 360-391.

HUNTINGTON, Samuel. (1975), A Ordem Política nas Sociedades em Mudança. Rio de Janeiro/São Paulo, Forense Universitária/EDUSP.

INÁCIO, Magna. (2009), “Mudança Procedimental, Oposições e Obstrução na Câmara dos Deputados", in M. Inácio e L. Rennó (eds.), O Legislativo Brasileiro em Perspectiva Comparada. Belo Horizonte, Ed. UFMG. 
Estrutura da Competição pela Presidência e Consolidação do Sistema Partidário...

(2006), Presidencialismo de Coalizão e Sucesso Presidencial na Esfera Legislativa. Tese de Doutorado, Programa de Pós-Graduação em Ciência Política da UFMG, Belo Horizonte.

KATZ, Richard e MAIR, Peter. (2002), "The Ascendancy of the Party in Public Office: Party Organization Change in Twentieth-Century Democracies", in R. Gunther, J. Monteiro e J. Linz (orgs.), Political Parties: Old Concepts and New Challenges. Oxford, Oxford University Press.

. (1995), “Changing Models of Party Organization and Democracy: The Emergence of the Cartel Party". Party Politics, vol. 1, no 1, pp. 5-28.

LAMOUNIER, Bolívar. (1989), Partidos e Utopias: O Brasil no Limiar dos Anos 90. São Paulo, Edições Loyola.

LEVITSKY, Steven. (2005), La Transformación del Justicialismo. Del Partido Sindical al Partido Clientelista. 1983-1999. Buenos Aires, Siglo XXI Editores.

LIMONGI, Fernando e CORTEZ, Rafael. (2010), “As Eleições de 2010 e o Quadro Partidário". Novos Estudos, no 88, pp. 21-37.

LUCAS, Kevin e SAMUELS, David. (2011), “A ‘Coerência' Ideológica do Sistema Partidário Brasileiro", in T. Power e C. Zucco Jr. (orgs.), O Congresso por Ele Mesmo: Autopercepções da Classe Política Brasileira. Belo Horizonte, Ed. UFMG.

. (2010), “The Ideological 'Coherence' of the Brazilian Party System, 1990-2009". Journal of Politics in Latin America, no 3, pp. 39-69.

LUNA, Juan Pablo e ALTMAN, David. (2011), “Uprooted but Stable: Chilean Parties and the Concept of Party System Institutionalization". Latin American Politics and Society, vol. 53, no 2, pp. 1-28.

LYNE, Mona. (2005), “Parties as Programmatic Agents”. Party Politics, vol. 11, no 2, pp. 193-216.

MAINWARING, Scott. (1999), Rethinking Party Systems in the Third Wave of Democratization. The Case of Brazil. Stanford, CA, Stanford University Press.

. (1992), "Brazilian Party Underdevelopment in Comparative Perspective". Political Science Quarterly, vol. 107, no 4, pp. 677-708.

. (1991), "Políticos, Partidos e Sistemas Eleitorais". Novos Estudos CEBRAP, no 29, pp. 34-58.

MAINWARING, Scott e SCULLY, Timothy (eds.). (1995), Building Democratic Institutions: Party Systems in Latin America. Stanford, Stanford University Press.

MAINWARING, Scott e TORCAL, Mariano. (2006), "Party System Institutionalization and Party System Theory after the Third Wave of Democratization", in R. Katz e W. Crotty (eds.), Handbook of Party Politics. London, Sage Publications.

(2005), "Teoria e Institucionalização dos Sistemas Partidários após a Terceira Onda de Democratização". Opinião Pública, vol. XI, no 2, pp. 249-286.

MAINWARING, Scott e ZOCO, Edurne. (2007), "Political Sequences and the Stabilization of Interparty Competition: Electoral Volatility in Old and New Democracies". Party Politics, vol. 13, no 2, pp. 155-178. 


\section{Carlos Ranulfo Melo e Rafael Câmara}

MAIR, Peter. (2006), "Party System Change", in R. Katz e W. Crotty (eds.), Handbook of Party Politics. London, Sage Publications.

. (1996), “Party Systems and Structures of Competition”, in L. Leduc, R. Niemi e P. Norris (orgs.), Comparing Democracies: Elections and Voting in Global Perspective. London, Sage Publications.

MANIN, Bernard. (1997), The Principles of Representative Government. Cambridge, Cambridge University Press.

. (1995), "Metamorfoses do Governo Representativo". Revista Brasileira de Ciências Sociais, vol. 10, no 29, pp. 5-34.

MELO, Carlos Ranulfo. (2011), “Individualismo e Partidarismo em Doze Estados da Federação". Revista Brasileira de Ciências Sociais, vol.26, № 75, pp. 57-72.

(2010), "Eleições Presidenciais, Jogos Aninhados e Sistema Partidário no Brasil". Revista Brasileira de Ciência Política, no 4, pp. 13-41.

. (2007), “Nem tanto ao Mar, nem tanto a Terra: Elementos para uma Análise do Sistema Partidário Brasileiro", in C. R. Melo e M. A. Sáez (eds.), A Democracia Brasileira: Balanço e Perspectivas para o Século 21. Belo Horizonte, Ed. UFMG.

. (2004), Retirando as Cadeiras do Lugar: Migração Partidária na Câmara dos Deputados (1985/2002). Belo Horizonte, Ed. da UFMG.

MENEGUELLO, Rachel. (2011), "Las Elecciones de 2010 y los Rumbos del Sistema de Partidos Brasileño: Política Nacional, Fragmentación y Lógica de Coaliciones", in M.

A. Saéz e M. L. Tagina (orgs.), America Latina: Política y Elecciones del Bicentenario (2009-2010). Madrid, Centro de Estudios Políticos y Constitucionales.

MIRANDA, Geralda Luiza. (2009), “A Influência da Dinâmica Eleitoral sobre o Comportamento dos Partidos na Câmara dos Deputados e no Senado Federal". DADOS, vol. 52, no 4, pp. 911-960.

MÜLLER, Wolfgang e STRØM, Kaare. (1999), Policy, Office or Votes? How Political Parties in Western Europe Make Hard Decisions. Cambridge, Cambridge University Press.

NEIVA, Pedro. (2011), “Disciplina Partidária e Apoio ao Governo no Bicameralismo Brasileiro". Revista de Sociologia Política, vol. 19, no 39, pp. 183-196.

NICOLAU, Jairo. (2000), “Disciplina Partidária e Base parlamentar na Câmara dos Deputados no Primeiro Governo Fernando Henrique Cardoso (1995-1998)". DADOS, vol. 43, no 4, pp. 709-736.

PANEBIANCO, Ângelo. (1982), Modelos de Partido. Madrid, Alianza Editorial.

PEREIRA, Carlos e MULLER, Bernardo. (2003), "Partidos Fracos na Arena Eleitoral e Partidos Fortes na Arena Legislativa: A Conexão Eleitoral no Brasil". DADOS, vol. 46, no 4, pp. 735-772.

POWER, Timothy e ZUCCO, Cesar. (2008), “Estimating Ideology of Brazilian Legislative Parties, 1990-2005: A Research Communication". Latin American Research Review, vol. 44, no 1, pp. 218-246.

RENNÓ, Lucio; PERES, Paulo e RICCI, Paolo. (2008), A Variação da Volatilidade Eleitoral no Brasil: Um Teste com as Explicações Econômicas, Políticas e Sociais. Trabalho 
Estrutura da Competição pela Presidência e Consolidação do Sistema Partidário...

apresentado no VI Encontro da Associação Brasileira de Ciência Política (ABCP), 29 de julho-1o de agosto, Unicamp, Campinas.

ROMA, Celso. (2002), “A Institucionalização do PSDB entre 1988 e 1998”. Revista Brasileira de Ciências Sociais, vol. 17, no 49, pp. 71-92.

SAMUELS, David. (2003), Ambition, Federalism and Legislative Politics in Brazil. New York, Cambridge University Press.

SANTOS, Fabiano. (2003), O Poder Legislativo no Presidencialismo de Coalizão. Belo Horizonte, Ed. UFMG.

SARTORI, Giovanni. (1996), Engenharia Constitucional: Como Mudam as Constituições. Brasília, Ed. UnB.

(1994), “Neither Presidentialism nor Parliamentarism”, in J. Linz e A. Valenzuela (eds.), The Failure of Presidential Democracy. Baltimore, MD, Johns Hopkins University Press.

. (1976), Partidos e Sistemas Partidários. Brasília, Ed. UnB.

SHUGART, Matthew e CAREY, John. (1992), Presidents and Assemblies. Cambridge, Cambridge University Press.

THELEN, Kathleen. (1999), "Historical Institutionalism in Comparative Politics". Annual Review of Political Science, no 2, pp. 369-404.

ZUCCO, Cesar. (2011), “Esquerda, Direita e Governo: A Ideologia dos Partidos Políticos Brasileiros", in T. Power e C. Zucco (orgs.), O Congresso por Ele Mesmo: Autopercepções da Classe Política Brasileira. Belo Horizonte, Ed. UFMG. 


\section{LISTA DE SIGLAS DOS PARTIDOS POLÍTICOS}

DEM - Democratas

PC do B - Partido Comunista do Brasil

PCB - Partido Comunista Brasileiro

PDS - Partido Democrático Social

PDT - Partido Democrático Trabalhista

PFL - Partido da Frente Liberal

PHS - Partido Humanista da Solidariedade

PMDB - Partido do Movimento Democrático Brasileiro

PMN - Partido da Mobilização Nacional

PP - Partido Progressista

PPS - Partido Popular Socialista

PR - Partido da República

PRB - Partido Republicano Brasileiro

PRN - Partido da Reconstrução Nacional

PSB - Partido Socialista Brasileiro

PSC - Partido Social Cristão

PSD - Partido Social Democrata

PSDB - Partido da Social Democracia Brasileira

PT - Partido dos Trabalhadores

PTB - Partido Trabalhista Brasileiro

PTC - Partido Trabalhista Cristão

PV - Partido Verde 
Estrutura da Competição pela Presidência e Consolidação do Sistema Partidário...

\section{ANEXO 1}

Bancadas na Câmara dos Deputados e Entrevistas Realizadas (2005)

\begin{tabular}{l|c|c|c|c}
\hline \multirow{2}{*}{ Partido } & \multicolumn{2}{|c|}{$\begin{array}{c}\text { Bancada na Câmara } \\
\text { (outubro/2005*) }\end{array}$} & \multicolumn{2}{c}{ Entrevistas Realizadas } \\
\cline { 2 - 5 } & $\mathbf{N}$ & $\mathbf{\%}$ & $\mathbf{N}$ & \% \\
\hline PMDB & 80 & 15,6 & 20 & 14,9 \\
PT & 82 & 16,0 & 23 & 17,2 \\
PSDB & 54 & 10,5 & 12 & 9,0 \\
PFL & 61 & 11,9 & 16 & 11,9 \\
PP & 54 & 10,5 & 14 & 10,4 \\
PSB & 29 & 5,7 & 06 & 4,5 \\
PDT & 20 & 3,9 & 03 & 2,2 \\
PR & 39 & 7,6 & 12 & 9,0 \\
PTB & 45 & 8,8 & 14 & 10,4 \\
PPS & 14 & 2,7 & 06 & 4,5 \\
PV & 08 & 1,5 & 02 & 1,5 \\
PC do B & 10 & 1,9 & 02 & 1,5 \\
PSC & 06 & 1,2 & 02 & 1,5 \\
Outros & 11 & 2,1 & 02 & 1,5 \\
\hline Total & 513 & $\mathbf{9 9 , 9}$ & $\mathbf{1 3 4}$ & $\mathbf{1 0 0 , 0}$ \\
\hline
\end{tabular}

* Fonte: Anuário estatístico do processo legislativo 2005. Site da Câmara dos Deputados.

Bancadas na Câmara dos Deputados e entrevistas realizadas (2010)

\begin{tabular}{l|c|c|c|c}
\hline \multirow{2}{*}{ Partido } & \multicolumn{2}{|c|}{$\begin{array}{c}\text { Bancada na Câmara } \\
\text { (fevereiro/2010*) }\end{array}$} & \multicolumn{2}{c}{ Entrevistas Realizadas } \\
\cline { 2 - 5 } & $\mathbf{N}$ & $\mathbf{\%}$ & $\mathbf{N}$ & $\%$ \\
\hline PMDB & 88 & 17,2 & 19 & 15,0 \\
PT & 77 & 15,0 & 23 & 18,1 \\
PSDB & 57 & 11,1 & 16 & 12,6 \\
DEM & 56 & 10,9 & 12 & 9,4 \\
PP & 38 & 7,4 & 8 & 6,3 \\
PSB & 27 & 5,3 & 7 & 5,5 \\
PDT & 23 & 4,5 & 5 & 3,9 \\
PR & 43 & 8,4 & 9 & 7,1 \\
PTB & 25 & 4,9 & 7 & 5,5 \\
PPS & 15 & 2,9 & 5 & 3,9 \\
PV & 15 & 2,9 & 4 & 3,1 \\
PC do B & 12 & 2,3 & 2 & 1,6 \\
PSC & 16 & 3,1 & 4 & 3,1 \\
PRB & 8 & 1,5 & 2 & 1,6 \\
Outros (PHS/PMN/PTC) & 13 & 2,5 & 4 & 3,1 \\
\hline Total & 513 & $\mathbf{9 9 , 9}$ & $\mathbf{1 2 7}$ & $\mathbf{9 9 , 9}$ \\
\hline
\end{tabular}

* Fonte: Site da Câmara dos Deputados. 


\section{ANEXO 2}

Coeficientes de Correlação (Pearson): Autoposicionamento na Escala Esquerda/Direita e Questões Utilizadas nos Surveys

\begin{tabular}{|c|c|c|}
\hline Questão & \begin{tabular}{|c} 
Autoposicio- \\
namento
\end{tabular} & Comentário \\
\hline ECON1 & $0,474 * *$ & \multirow{5}{*}{$\begin{array}{l}\text { Parlamentares que se posicionam à } \\
\text { esquerda preferem uma maior pre- } \\
\text { sença do estado na economia. }\end{array}$} \\
\hline ECON2 & $0,346 * *$ & \\
\hline ECON3 & $0,578 * *$ & \\
\hline ECON4 & $0,382 * *$ & \\
\hline ECON5 & $0,484 * *$ & \\
\hline EXT3 (EUA) & $0,361^{* *}$ & \multirow{3}{*}{$\begin{array}{l}\text { Parlamentares posicionados à direi- } \\
\text { ta avaliam de forma mais positiva a } \\
\text { relação com os EUA e a entrada na } \\
\text { ALCA; por outro lado avaliam de } \\
\text { forma negativa a ALBA. }\end{array}$} \\
\hline EXT4 (ALCA) & $0,494 * *$ & \\
\hline EXT5 (ALBA) & $-0,357^{* *}$ & \\
\hline EXT7 (Lula) & $-0,352^{* *}$ & \multirow{3}{*}{$\begin{array}{l}\text { Parlamentares que se posicionam } \\
\text { mais à direita tendem a avaliar de } \\
\text { forma mais negativa esses três líde- } \\
\text { res políticos. }\end{array}$} \\
\hline EXT8 (Morales) & $-0,656^{* *}$ & \\
\hline EXT9 (Chaves) & $-0,572^{* *}$ & \\
\hline VAL1 & $-0,307^{* *}$ & \multirow{2}{*}{$\begin{array}{l}\text { Parlamentares que se posicionam } \\
\text { mais à direita tendem a ser contrári- } \\
\text { os à descriminalização do aborto e à } \\
\text { união entre pessoas do mesmo sexo. }\end{array}$} \\
\hline VAL2 & $-0,503^{* *}$ & \\
\hline PART1 & $-0,268^{* *}$ & $\begin{array}{l}\text { Parlamentares que se posicionam } \\
\text { mais à direita tendem a ser menos } \\
\text { favoráveis à expulsão de parlamen- } \\
\text { tar que vota contra as determina- } \\
\text { ções do partido. }\end{array}$ \\
\hline $\begin{array}{l}\text { Deputados favoráveis a que se exija } \\
\text { a disciplina partidária sempre que o } \\
\text { partido defina posição (2010) }\end{array}$ & $-0,246^{* *}$ & $\begin{array}{l}\text { Deputados mais à direita tendem a } \\
\text { ser menos favoráveis à exigência de } \\
\text { disciplina. }\end{array}$ \\
\hline $\begin{array}{l}\text { Deputados que declaram votar com } \\
\text { o partido em caso de conflito com os } \\
\text { interesses do estado (2005) }\end{array}$ & $0,402^{* *}$ & $\begin{array}{l}\text { Deputados situados mais à esquer- } \\
\text { da se declaram mais dispostos a vo- } \\
\text { tar com o partido. }\end{array}$ \\
\hline $\begin{array}{l}\text { Deputados que declaram votar com } \\
\text { o partido em caso de conflito com os } \\
\text { interesses do estado (2010) }\end{array}$ & $0,233^{* *}$ & $\begin{array}{l}\text { Deputados situados mais à esquer- } \\
\text { da se declaram mais dispostos a vo- } \\
\text { tar com o partido. }\end{array}$ \\
\hline $\begin{array}{l}\text { Deputados favoráveis a que se re- } \\
\text { nuncie à cadeira em caso de troca de } \\
\text { partido (2010) }\end{array}$ & $-0,211^{* *}$ & $\begin{array}{l}\text { Deputados situados mais à direita } \\
\text { são menos favoráveis à renúncia em } \\
\text { caso de migração partidária. }\end{array}$ \\
\hline
\end{tabular}

Elaboração dos autores. 


\begin{abstract}
Structure of the Presidential Race and Consolidation of the Party System in Brazil

In this article, the authors: (1) argue that the structure of the Brazilian Presidential race represents the decisive factor in the recent consolidation of the country's party system; (2) identify three distinct party blocs based on an analysis of the strategies developed by the parties within the Presidential race; (3) examine the blocs' positions based on surveys conducted in the Chamber of Deputies in 2005 and 2010; and (4) demonstrate that the situation in the electoral sphere has its correlate at the Congressional level, allowing an ideological distinction between two of these blocs, while the third bloc calculates its moves exclusively on the disconnect between government and opposition.
\end{abstract}

Key words: Presidential elections; party blocs; Chamber of Deputies

\title{
RÉSUMÉ
}

Structure de la Course à la Présidentielle et Consolidation du Système des Partis au Brésil

Dans cet article, (1) on propose que la structure adoptée par la course à la Présidence de la République représente le facteur décisif dans les récents mécanismes de consolidation du système brésilien des partis; (2) on a relevé trois blocs différents de partis d'après l'analyse des stratégies qu'ils mettent en œuvre au sein de cette compétition; (3) on a examiné leurs positions à partir de sondages effectués dans la Chambre des Députés en 2005 et 2010; et (4) on constate dans la sphère électorale un cadre équivalent à celui du parlement, ce qui permet d'établir une distinction d'ordre idéologique entre ces deux blocs, tandis qu'un troisième conduit ses actions en ne tenant compte que de la disjonctive gouvernement/opposition.

Mots-clés: élections présidentielles; blocs de partis; Chambre des Députés 